Article

\title{
Analysis of Indoor Air Pollutants and Guidelines for Space and Physical Activities in Multi-Purpose Activity Space of Elementary Schools
}

\author{
Yeo-Kyung Lee ${ }^{1}$ and Young Il Kim ${ }^{2, *}$ \\ 1 Department of Architectural Engineering, Graduate School, Seoul National University of Science and Technology, \\ Seoul 01811, Korea; dldurud9004@naver.com \\ 2 School of Architecture, Seoul National University of Science and Technology, Seoul 01811, Korea \\ * Correspondence: yikim@seoultech.ac.kr
}

check for updates

Citation: Lee, Y.-K.; Kim, Y.I. Analysis of Indoor Air Pollutants and Guidelines for Space and Physical Activities in Multi-Purpose Activity Space of Elementary Schools. Energies 2022, 15, 220. https://doi.org/ $10.3390 /$ en15010220

Academic Editor: Boris Igor Palella

Received: 15 November 2021

Accepted: 22 December 2021

Published: 29 December 2021

Publisher's Note: MDPI stays neutral with regard to jurisdictional claims in published maps and institutional affiliations.

Copyright: (C) 2021 by the authors. Licensee MDPI, Basel, Switzerland. This article is an open access article distributed under the terms and conditions of the Creative Commons Attribution (CC BY) license (https:// creativecommons.org/licenses/by/ $4.0 /)$.

\begin{abstract}
Owing to the recent increase in the number of warning reports and alerts on the dangers of fine dusts, there has been an increasing concern over fine dusts among citizens. In spaces with poor ventilation, the occupants are forced to open the window to initiate natural ventilation via the direct introduction of the outside air; however, this may pose a serious challenge if the external fine-dust concentration is high. The lack of natural ventilation increases the indoor carbon dioxide $\left(\mathrm{CO}_{2}\right)$ concentration, thus necessitating the installation of mechanical ventilation systems. This study analyzed the frequency of the application of mechanical ventilation systems in the Multi-purpose activity space of elementary schools, which are spaces where children require a higher indoor air quality than adults owing to the rapid increase in the $\mathrm{CO}_{2}$ concentration of the Multi-purpose activity space during activities. In addition, the architectural and equipment factors of the Multi-purpose activity spaces of nine elementary schools were characterized. The results revealed that five out of the nine elementary schools installed mechanical ventilation systems, whereas the remaining four schools installed jet air turnover systems. The indoor air quality of the Multi-purpose activity space of D elementary school, which had the minimum facility volume among the schools investigated in this study $\left(564.2 \mathrm{~m}^{3}\right)$, with up to 32 participants for each activity, was investigated. The results revealed that the ultrafine-dust (PM2.5) concentration of the facility was as high as $4.75 \mu \mathrm{g} / \mathrm{m}^{3}$ at a height of $1.2 \mathrm{~m}$, and the $\mathrm{CO}_{2}$ concentration was as high as $3183 \mathrm{ppm}$. The results of the analysis of three elementary schools with different volumes were compared and analyzed using CONTAM simulation. This study determined the required volume per occupant and the optimum number of occupants for a given volume and presented guidelines for the optimum number of occupants, activities, and volume to reduce the high concentration of pollutants in the analyzed Multi-purpose activity space. The guideline proposed in this study is aimed at maintaining the $\mathrm{CO}_{2}$ concentration of the Multi-purpose activity space below 1000 ppm, as prescribed by the Indoor Air Quality Control in Public-Use Facilities, Etc. Act in South Korea.
\end{abstract}

Keywords: activity; carbon dioxide; jet air turnover system; CONTAM; elementary school; fine dust; indoor air quality; Multi-purpose activity space (MPA-space); student

\section{Introduction}

\subsection{Background and Objectives of Research}

Currently, in Korea, the number of warnings due to fine dust is increasing every year. The domestic fine-dust measurement data are divided into PM10 and PM2.5. According to 'Fine, Ultrafine, and Yellow Dust: Emerging Health Problems in Korea' [1], PM10 with a diameter of less than $10 \mu \mathrm{m}$ is classified as fine dust, and PM2.5 with a diameter of less than $2.5 \mu \mathrm{m}$ is classified as ultrafine dust. In the case of PM2.5, the dust is deposited in the alveolar region and has a worse effect on health than PM10 (fine dust) [1,2]. In particular, 
when comparing the concentration of ultrafine dust in Seoul and five major overseas cities for 6 years, from 2014 to 2019, as analyzed using the domestic air environment annual data and the China Environmental Observation Center data [3], the ultrafine particles in Seoul are gradually increasing each year, a trend contrary to other major populated cities, as shown in Figure 1. The dust concentration of Seoul was measured to be the second highest after Beijing. Compared to the four cities of LA, Tokyo, Paris, and London, it can be seen that the concentration of ultrafine dust in Seoul is measured as being twice as high [4].

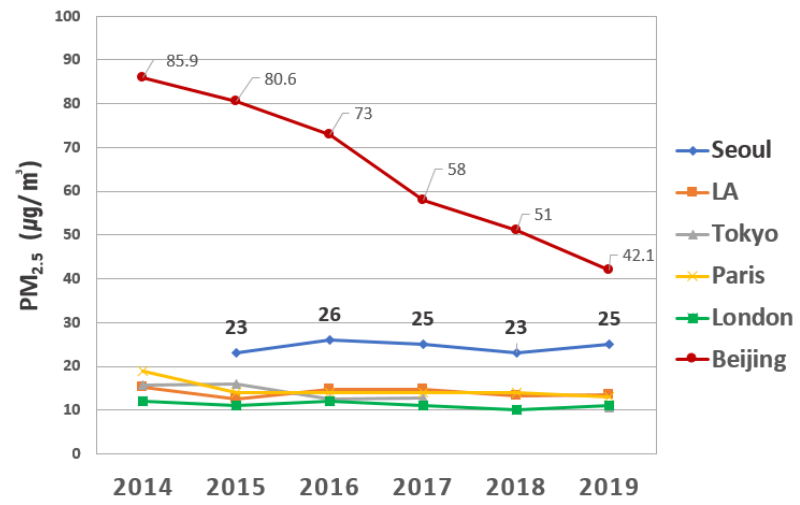

(a)

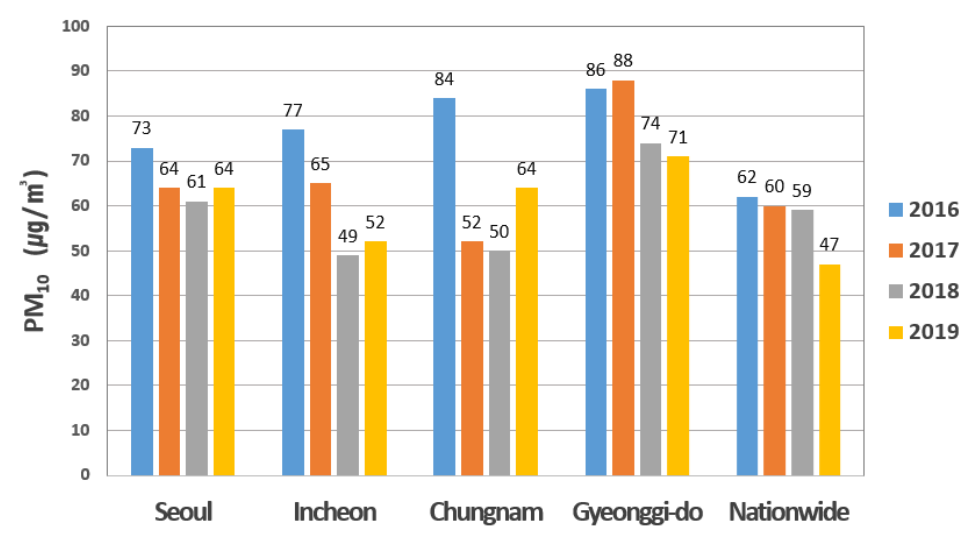

(b)

Figure 1. (a) Annual ultrafine-dust (PM2.5) concentration in the major cities of the world [4]; (b) annual fine-dust (PM10) concentration in Korea [4].

In addition, the 'Annual Report of Air Quality in Korea 2019' revealed that the concentration of ultrafine dusts in Seoul was approximately twice as high as those of Los Angeles, Tokyo, Paris, and London [5]. In China, where the high concentration of fine dust has posed a serious environmental threat, the fine-dust concentration has been decreasing annually, whereas that of South Korea has been increasing. In addition, in the '2019 World Air Quality Report' of IQAir, an international air-pollutant protection technology organization, South Korea was ranked first in the ultrafine-dust concentration among OECD member states [5]. In addition, a report on the Chungnam region, which is located in the center of South Korea, revealed that the increase in fine-dust concentration is a major cause of the deterioration in the public health of this region. This could be attributed to the significantly high emission of air pollutants in the Chungnam region owing to the industries which greatly rely on combustion processes in this region [6]. According to the 'fine dust alert status report' of the Chungnam Institute of Health and Environment, as of 6 May 2017 the average hourly fine-dust concentration in the Chungnam area was measured to be higher than $300 \mu \mathrm{g} / \mathrm{m}^{3}$ during the hours of 13:00 to 18:00 [6,7]. In the Chungnam region, the annual average number of asthma patients per 100,000 people is 6259 , and correlation analysis results on the identification of the effects of air pollutants, such as fine dust, revealed that this number increases with an increase in the emissions of suspended particulates and fine dusts [5]. In addition, a high incidence of respiratory diseases was observed among the residents in Incheon, which exhibits a relatively high concentration of air pollutants [8]. Children are more vulnerable to the adverse effects of fine dusts compared to adults owing to their body structure, behavior, and developmental characteristics [9]. Furthermore, the "High-concentration Fine Dust Response Manual for Protection of the Vulnerable Class" describes that infants and children inhale more air pollutants than adults because of their higher respiratory rate per unit weight [10,11]. Air pollutants have an adverse effect on human health and are particularly dangerous for infants and children with underdeveloped lungs [12]. There is an increasing awareness about the protection of elementary school students from exposure to external fine dusts owing to the increasing concerns about the direct adverse effects of air pollutants on human health, and the increasing reports on the dangers of fine dust. However, the lack of attention to the importance of proper ventila- 
tion in daily life has resulted in occupants devoting little time to opening windows and ventilating their indoor space $[13,14]$. Insufficient natural ventilation results in an increase in the indoor carbon dioxide $\left(\mathrm{CO}_{2}\right)$ concentration, thus necessitating the installation of a mechanical ventilation system [15]. Thus, this study aimed to analyze the frequency of the application of mechanical ventilation systems in the MPA-spaces of elementary schools, as well as the characteristics of the pollutants in spaces with high activity levels of children.

\subsection{Scope and Methodology of Research}

This study examined various comprehensive measures and legal standards implemented by the government in elementary school facilities with an increase in the concentration of fine dust, and further analyzed the frequency of the installation of mechanical ventilation systems in the indoor MPA-spaces of elementary schools with high activity levels of elementary school students. In addition, the $\mathrm{CO}_{2}$ concentration and the fine-dust concentration were measured as a function of the activity levels of elementary school students, using Testo 160 IAQ and Sensirion SPS, respectively. The airtightness of the facilities was measured using a blower door test, as shown in Figure 2.

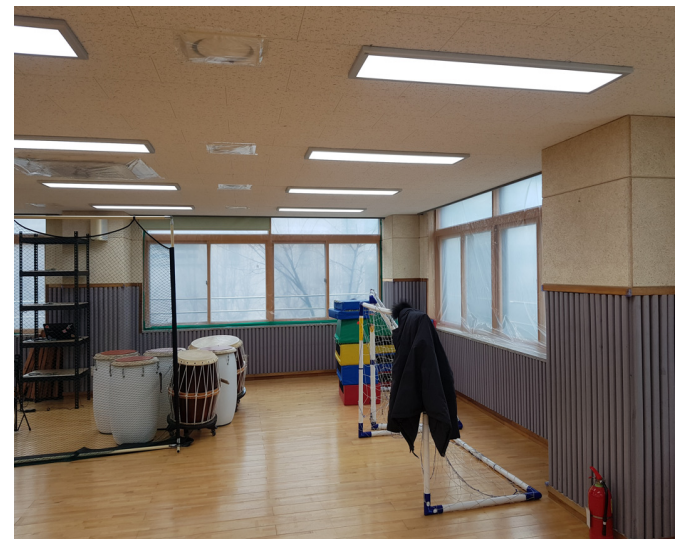

(a)

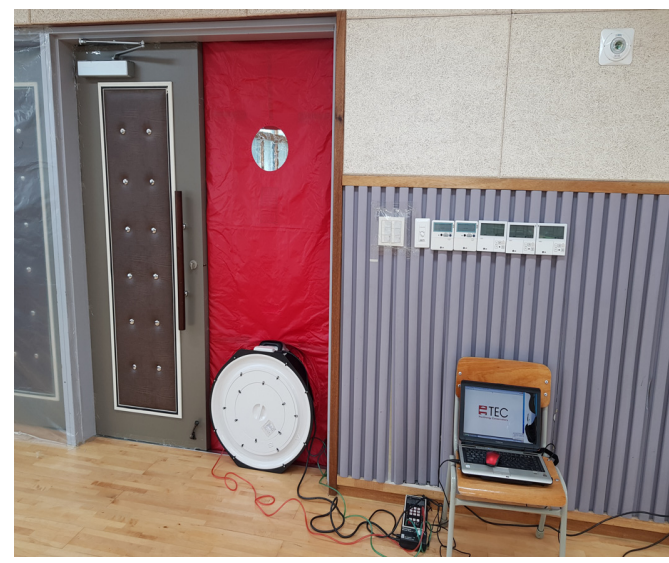

(b)

Figure 2. (a) Sealing of windows, doors, diffusers, air conditioners, and other openings before the blower door test; (b) blower door test of the MPA-space of D Elementary school.

Through the experimental results and graph analysis, the indoor-air-pollutant concentration increase over time, with respect to the number of occupants and activities and the correlation between the space volume and the pollutant concentration, can be found. The rate of increase in air pollutants as a function of the activity levels of elementary school students was measured using experimental results, and the change in pollutant concentrations at three elementary schools with different MPA-space volumes was compared using CONTAM (W. Stuart Dols, Brian J. Polidoro, Gaithersburg, US) simulation. In addition, the required volume per occupant and the permissible number of occupants in a facility was derived using CONTAM simulation to determine the conditions necessary to reduce the concentration of air pollutants in these MPA-spaces to below the minimum acceptable level and to provide guidelines on the optimum number of people, activities, and volume [16,17].

The CONTAM simulation results were verified by comparing the root mean square error (RMSE) and the mean absolute percentage error (MAPE) of the simulation and measurement results. For the design guidelines and for suggesting the proper level of activities in indoor physical spaces and the correlations between activity types, the number of people, the space, the activity time, and the $\mathrm{CO}_{2}$ concentration were derived in order to maintain a $\mathrm{CO}_{2}$ concentration in indoor space below $1000 \mathrm{ppm}$. If the indoor physical spaces were operated using these correlations, the indoor-air-quality environment was affected positively and enhanced the effectiveness of student physical activities and the indoor occupants' health [9-11]. 


\section{Domestic System and Class Status of the MPA-Space of Elementary Schools}

This study investigated the standards and comprehensive measures implemented by the government to respond to the annually increasing concentration of fine dusts in the MPA-spaces of elementary schools and the guidelines of the Ministry of Education on the "watch" and "warning messages" of the domestic fine-dust warning systems of the physical education activities of elementary schools.

\subsection{Comprehensive Measures for Reducing the Concentration of Fine Dusts in South Korea}

The South Korean Government has recognized the increasing tendency and hazard of fine dusts and has been preparing various comprehensive measures and legal standards. As a part of these efforts, the South Korean Government recently included provisions on air quality in the School Health Act in 2019, which is the most closely related provision for elementary schools. Furthermore, the Ministry of Environment recently announced the standards for facilities used by the vulnerable class, and the Office of Education on metropolitan and provincial levels distributed practical manuals on the response to highconcentration fine dusts in order to prepare the rules that should be adhered to by school facilities in responding to the occurrence of high-concentration fine dusts. These include the replacement of outdoor physical education classes with indoor classes or the reduction in the duration of outdoor activities when "watch" or "preliminary/emergency reduction measures" messages on the fine dusts are issued [18]. In summary, national comprehensive measures and standards are being established to address the increase in the concentration of fine dusts in South Korea, and regulations on outdoor activities are being strengthened.

\subsection{Current Status of Physical Education Classes According to the Domestic System in Response to Fine Dusts}

The "watch" or "preliminary/emergency reduction measures" messages on fine dust, from the standards on national comprehensive measures and the practical manual of the Office of Education on metropolitan and provincial levels, restrict outdoor physical education classes [18]. According to a previous study on the "Effects of Elementary School Students" Awareness of Fine Dust, Respiratory-Related Subjective Symptoms, and Level of Physical Activities on Health Promotion Behavior," [19] children's physical activity at school and at home decreased as the concentration of fine dust increased. In addition, according to "A Qualitative Case Study on Physical Education Classes for Efforts to Overcome Fine Dust," [20] the importance of indoor physical education classes is increasing. However, because of the insufficient analyses and studies on the quantity of fine dusts in indoor MPA-spaces, compared to that of regular classrooms, it is difficult to identify the exact characteristics of the MPA-space owing to insufficient data on the aging MPA-spaces of schools. Therefore, this study analyzed the architectural and equipment factors of the MPA-space of elementary schools, as well as the change in the concentration of fine dusts and $\mathrm{CO}_{2}$ as a function of the activities during physical education class.

\section{Current Status of Indoor MPA-Spaces in Elementary Schools}

This study analyzed the architectural and equipment factors of the MPA-space in elementary schools to examine the current indoor environment of these facilities.

\subsection{Architectural Factors of the Indoor MPA-Space in the Elementary Schools}

This study analyzed the architectural factors of the MPA-space in nine elementary schools using architectural drawings of these facilities. The data on the required area per student, which were obtained using the average floor area of the MPA-space and the information on the school alert site, were analyzed [21]. The analysis of the size of the MPA-space in the nine elementary schools revealed that the average floor area and ceiling height of the facilities was $609.82 \mathrm{~m}^{2}$ and $9.96 \mathrm{~m}$, respectively (Table 1). 
Table 1. Height, area, and volume of the MPA-space of the nine elementary schools.

\begin{tabular}{cccc}
\hline Name of School & Ceiling Height $\mathbf{( m )}$ & Floor Area $\left.\mathbf{( m}^{\mathbf{2}}\right)$ & Space Volume $\mathbf{( m}^{\mathbf{3}} \mathbf{)}$ \\
\hline A & 10.4 & 616.14 & 6407.9 \\
B & 10.8 & 677.16 & 7313.3 \\
C & 10.6 & 751.20 & 7962.7 \\
D & 3.64 & 155 & 564.2 \\
E & 10.6 & 562.8 & 5965.7 \\
F & 11.5 & 570.72 & 6563.3 \\
G & 12.1 & 725.4 & 8777.3 \\
H & 9.46 & 652.4 & 6171.7 \\
I & 10.5 & 777.6 & 8164.8 \\
\hline Average & 9.96 & 609.82 & 6073.8 \\
\hline
\end{tabular}

The required area of $0.4 \mathrm{~m}^{2}$ per person, which is the stipulated required auditorium area in the school facility planning and design guidelines of the Seoul Metropolitan Office of Education, and in the general applications of domestic building plans, was compared to the floor area of the nine elementary schools (Table 2). The results revealed that the actual floor area of the MPA-space of eight out of the nine analyzed elementary schools satisfied the criterion; however, the D Elementary School, which was established in 1965, did not meet the criterion $[22,23]$.

Table 2. Required area for the MPA-space of the elementary schools.

\begin{tabular}{cccc}
\hline Name of School & Number of Classes & Number of Students & $\begin{array}{c}\text { Required Area } \\
\text { (Number of Students } \times \mathbf{0 . 4} \mathbf{~ m}^{\mathbf{2}} \text { ) }\end{array}$ \\
\hline A & 28 & 729 & 291.56 \\
B & 28 & 889 & 355.6 \\
C & 24 & 579 & 231.6 \\
D & 25 & 445 & 178 \\
E & 28 & 1224 & 489.6 \\
F & 32 & 1062 & 424.8 \\
G & 28 & 850 & 340 \\
H & 29 & 1263 & 505.2 \\
I & 22 & 823 & 329.2 \\
\hline Average & 26.64 & 854.73 & 341.9 \\
\hline
\end{tabular}

\subsection{Equipment Factors of the Indoor MPA-Space in the Elementary Schools}

The current status of the air purification systems in the MPA-space of the nine elementary schools was analyzed, and the results revealed that air conditioning systems were installed in all the MPA-spaces (Table 3). The air conditioning and heating devices used in these schools included a gas-engine-driven heat pump (GHP) and an electric heat pump (EHP). Jet air turnover systems are beneficial in seasons with poor air stream for reducing the temperature difference between the upper and lower temperatures in the room. In this study, jet air turnover systems were installed in four out of the nine elementary schools [24].

In addition, poorly operating diffusers were observed in the D elementary school; however, an energy recovery ventilation (ERV) system was installed in the MPA-space of the school. These results suggest that the distribution of air conditioners in the indoor MPA-spaces in these schools is insufficient, and some of the mechanical ventilation systems in these schools were in poor operation and required immediate improvement.

Therefore, this study further investigated the indoor air quality of the D elementary school to analyze the effects of the required area on the indoor air quality, as well as the concentration of the indoor air pollutants requiring mechanical ventilation application. 
Table 3. Status of the air conditioners and air purifiers in the analyzed elementary schools.

\begin{tabular}{ccc}
\hline Name of School & Air Conditioning and Heating Device & Air Purifier \\
\hline A & GHP & Jet air turnover system \\
B & EHP & Jet air turnover system \\
C & GHP & X \\
D & GHP & ERV \\
E & GHP & Jet air turnover system \\
F & EHP & Jet air turnover system \\
G & EHP & X \\
H & EHP & Fan \\
I & GHP & Fan \\
\hline
\end{tabular}

\section{Analysis of the Indoor Air Quality Characteristics Based on the Volume of the MPA-Space}

Indoor air quality was measured to analyze the indoor environmental characteristics that change according to students' activities at indoor physical education facilities in elementary schools. The experiment measured the indoor temperature, which affects the comfort of the occupants, and the concentration of $\mathrm{CO}_{2}$ that adversely affects the human body as the concentration increases, in addition to the concentration of fine dusts.

The D Elementary School was established in 1965, and its MPA-space is located on the second floor. In the case of the MPA-space, as shown in Figure 3, the floor area is $155 \mathrm{~m}^{2}$, the ceiling height is $3.64 \mathrm{~m}$, and the volume is $564.2 \mathrm{~m}^{3}$. The space is heated and cooled by EHP with an ERV and air purifier installed.

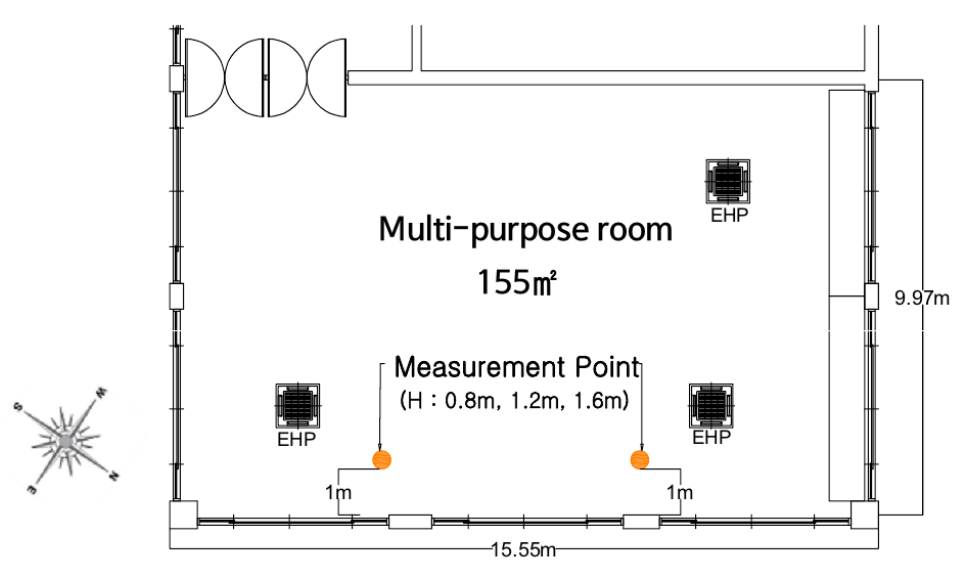

(a)

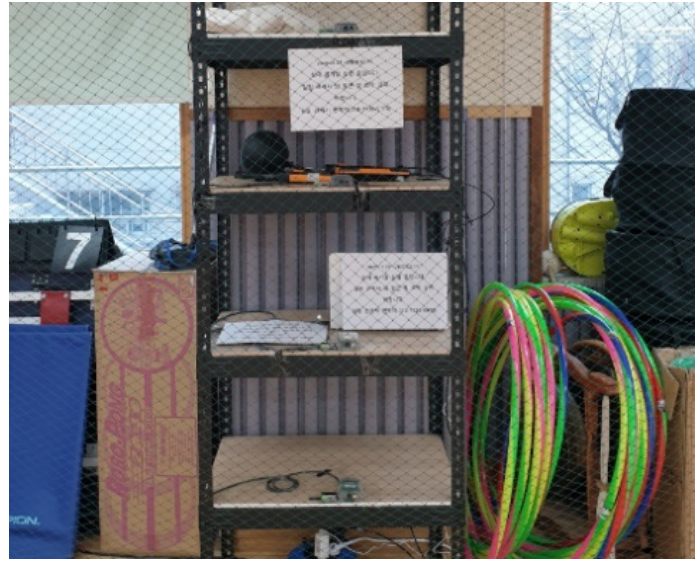

(b)

Figure 3. (a) Floor plan of the MPA-space of the D elementary school and (b) indoor-air-quality measurement experiment.

\subsection{Indoor Air Quality Experiment of the MPA-Space}

The indoor air quality factors, including temperature, humidity, $\mathrm{CO}_{2}, \mathrm{PM} 10$, and PM2.5 from 30 January 2020 to 4 February 2020, were measured. The concentration of fine dust, the temperature, and the $\mathrm{CO}_{2}$ concentration were measured using the Sensirion SPS30, which is certified by the Monitoring Certification Scheme (MCERTS), a monitoring certification of the UK Environment Agency, and the Testo 400, respectively. The MPAspace of the D Elementary School is utilized for various physical education activities, such as club activities, small soccer, badminton, and playing catch.

As shown in Figure 3, the ultrafine-dust measurement points were measured at two measurement points with heights of $0.8 \mathrm{~m}, 1.2 \mathrm{~m}$, and $1.6 \mathrm{~m}$, respectively. For the outdoor air data, the 'Ambient air information around our school' measurement data provided by the Korea Environment Corporation was used [25]. Figure 4 shows the result of the finedust concentration measured on January 30 , when various activities were being performed 
in the facility. On January 30, the MPA-space was ventilated by teachers for 5 to $10 \mathrm{~min}$ before the elementary school students started their activities (Table 4).

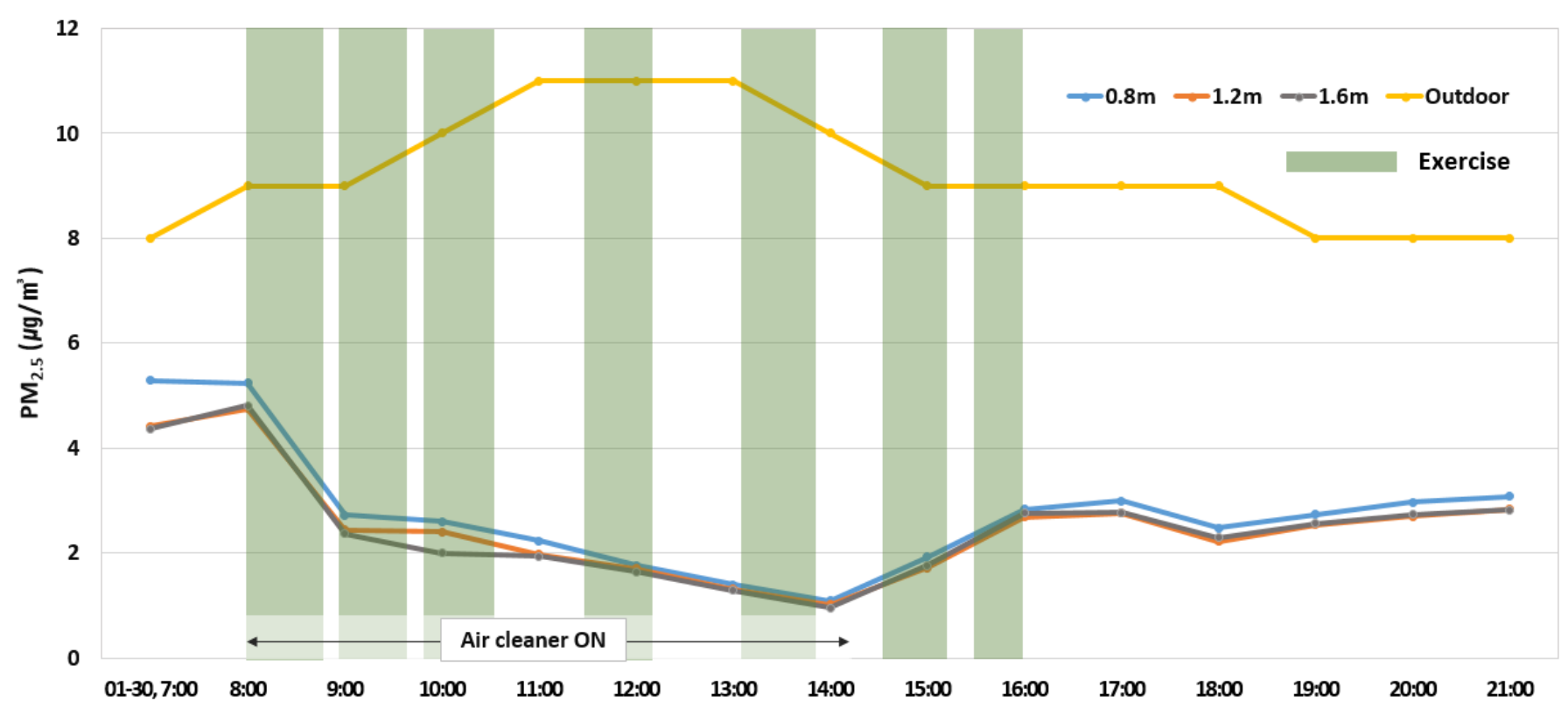

Figure 4. Measurement of ultrafine-dust (PM2.5) concentration in the MPA-space of D elementary school on 30 January 2020 as a function of the physical activities.

Table 4. Activity schedule of the MPA-space of D elementary school on 30 January 2020.

\begin{tabular}{ccccc}
\hline Time & Activity Type & $\begin{array}{c}\text { Number of } \\
\text { Occupants }\end{array}$ & Air Purifier & $\begin{array}{c}\text { Ventilation } \\
\text { before Activity }\end{array}$ \\
\hline 08:00-08:50 & Extracurricular activity & 32 & On & O \\
09:00-09:40 & Catch play & 25 & On & O \\
09:50-10:30 & Catch play & 24 & On & O \\
11:30-12:10 & Catch play & 24 & On & O \\
13:10-13:50 & Catch play & 25 & On & O \\
14:35-15:10 & After-school activity & 12 & Off & O \\
15:30-15:55 & After-school activity & 12 & Off & X \\
\hline
\end{tabular}

The measurement of the ultrafine-dust concentration revealed that the number of occupants and activities had no significant effect on the ultrafine-dust concentration; however, the concentration drastically decreased when the operation of the air purifier was initiated at 8:00 am (Figure 4). In contrast, the indoor ultrafine-dust concentration gradually increased from 14:00 when the air purifier was not in operation. Nevertheless, the concentration of ultrafine dust in the facility was maintained at a significantly lower concentration than $35 \mu \mathrm{g} / \mathrm{m}^{3}$, which is the standard concentration in 'Annex 2 Maintenance Standards' of the Enforcement Rule of the Domestic Indoor Air Quality Control Act [1].

However, the trend in the effect of the activities of the occupants on the $\mathrm{CO}_{2}$ concentrations was significantly different from that of the fine-dust concentration. Despite the ventilation initiated by the teachers for 5-10 min prior to the physical education class, the data measured at $1 \mathrm{~min}$ intervals at a height of $1.2 \mathrm{~m}$ and analyzed for an average of $5 \mathrm{~min}$, revealed that the maximum $\mathrm{CO}_{2}$ concentration for each activity was as high as $3183 \mathrm{ppm}$. In particular, the number of occupants and activities had a significant effect on the increase in the $\mathrm{CO}_{2}$ concentrations (Figure 5), which exceeded the domestic concentration limit of the Enforcement Rules of the Indoor Air Quality Control in Public-Use Facilities, Etc. Act $[26,27]$. 


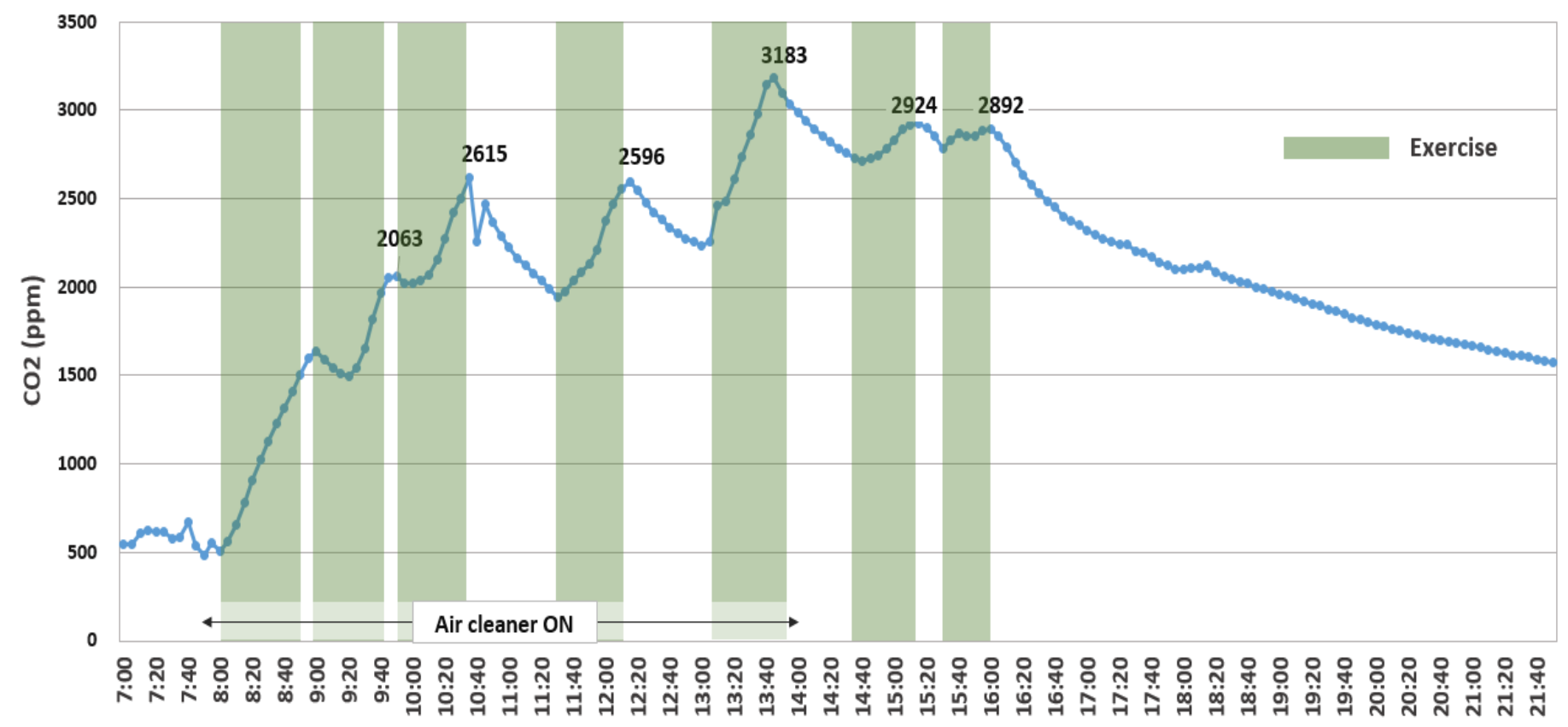

Figure 5. Result of the carbon dioxide $\left(\mathrm{CO}_{2}\right)$ concentration by physical activity in MPA-space in D elementary school on 30 January 2020.

To analyze the $\mathrm{CO}_{2}$ concentration, which is the most problematic in this type of space, this study analyzed the effect of the physical activities and the number of occupants on the $\mathrm{CO}_{2}$ concentration using CONTAM simulation. In addition, the airtightness of the MPA-space was measured using a blower door test [28].

The airtightness test was conducted using a blower door (Minneapolis Blower Door ${ }^{\mathrm{TM}}$ System, TEC, USA). To measure the airtightness, first each opening element affecting the airtightness of the applicable space was sealed, after which the sealing materials were removed sequentially. As shown in Table 5, the opening elements included the windows in the MPA-space, the supply and exhaust ducts, an indoor EHP, and a door. Pressurization and depressurization methods (EN 13829) were employed during the blower door test to seal the exterior- and corridor-side window systems, which were expected to be major intrusion paths for fine dust, and to remove the plastic pasted during the sealing of each element until the pressure difference between indoor and outdoor environment was -10-65 Pa [29-31].

Table 5. Leakage area of the MPA-space.

\begin{tabular}{|c|c|c|c|c|c|}
\hline & Element & $\begin{array}{l}\text { Cumulative EqLA } \\
\qquad\left(\mathrm{cm}^{2}\right)\end{array}$ & $\begin{array}{l}\text { Cumulative Surface Area } \\
\qquad\left(\mathrm{cm}^{2} / \mathrm{m}^{2}\right)\end{array}$ & $\begin{array}{l}\text { EqLA } \\
\left(\mathrm{cm}^{2}\right)\end{array}$ & $\begin{array}{l}\text { Surface Area } \\
\left(\mathrm{cm}^{2} / \mathrm{m}^{2}\right)\end{array}$ \\
\hline 1 & Element sealing & 1941.9 & 3.98 & 1941.90 & 3.98 \\
\hline 2 & Small window & 2011.5 & 4.12 & 69.60 & 0.14 \\
\hline 3 & Supply air diffuser & 2286.5 & 4.69 & 129.80 & 0.27 \\
\hline 4 & Exhaust air diffuser & 2387.3 & 4.89 & 100.80 & 0.20 \\
\hline 5 & EHP & 2410.9 & 4.94 & 23.60 & 0.05 \\
\hline 6 & Large window & 2589.7 & 5.31 & 178.1 & 0.37 \\
\hline 7 & Door & 2913.5 & 5.97 & 323.80 & 0.66 \\
\hline
\end{tabular}

The airtight performance measured using the blower door test can be represented using several units, such as $\mathrm{ACH}$ (Air Change per Hour) and ELA (Effective Leakage Area). In this study, the measured airtight performance was represented using Equivalent Leakage Area (EqLA), as shown in Table 5. The EqLA corresponded to the amount of leaked air as a function of the area when the pressure difference between the inside and outside environment of a building was $10 \mathrm{~Pa}$ [32]. 
Furthermore, the results of the analysis of the natural ventilation rate using the air volume ranging from 10 to $65 \mathrm{~Pa}$ are represented in the trend line shown in Table 6 . The amount of natural ventilation at $2 \mathrm{~Pa}$, which is the standard pressure difference for installing natural ventilation facilities according to the Annex Tables 1-3 of the Rules on Equipment Standards for Domestic Buildings, was significantly high (1.58 per hour) [33]. This result indicates that the external air exchange in this facility was active.

Table 6. Change in the air flow rate per hour of the MPA-space of D elementary school.

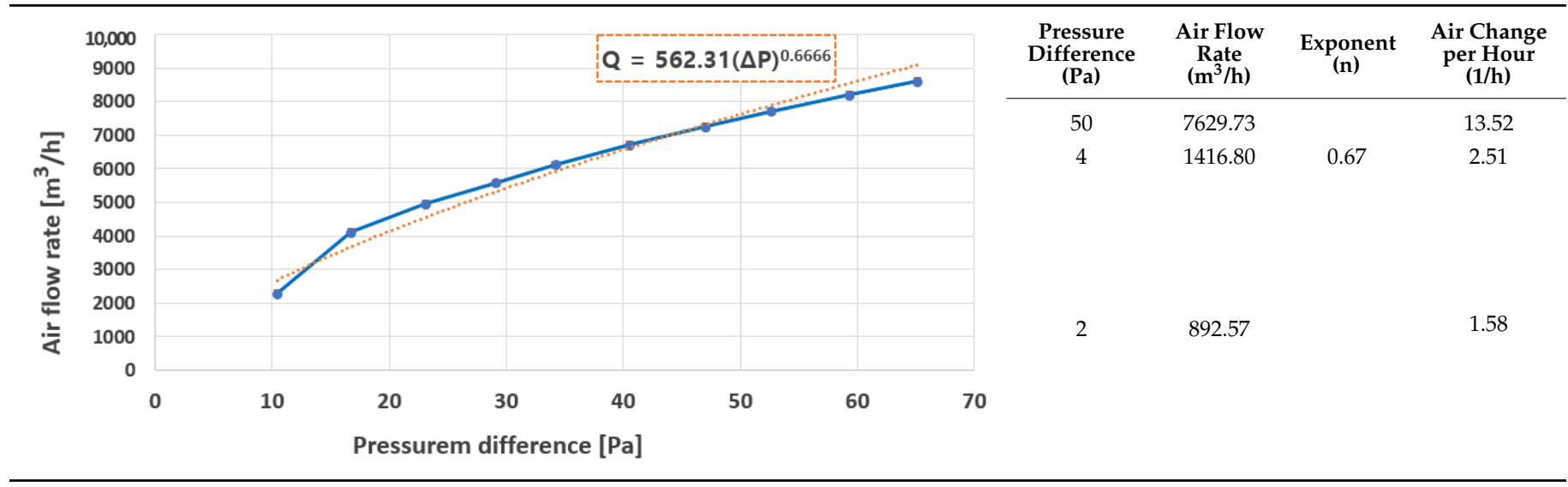

\subsection{Simulation Analysis of the MPA-Space}

To determine the effect of the number of occupants and the leakage area conditions on the change in the $\mathrm{CO}_{2}$ concentration of the MPA-space of D elementary school, with a change in the volume of the facility during the same activity, the change in the $\mathrm{CO}_{2}$ concentration of three elementary schools with different facility volumes was simulated using CONTAM. The results presented in Table 1 indicate that the D elementary school exhibits the worst physical activity facility conditions because of its large number of occupants per unit volume and the poor operation of its facility in introducing outdoor air due to aging.

In contrast, the analysis of the architectural drawings of the A and $\mathrm{H}$ elementary schools, which corresponded to Cases 2 and 3, revealed that their MPA-spaces were good as their floor area and height were on an average level. Cases 2 and 3 were selected because their data can be used for standard model analysis in future studies, and the results will be highly useful in designs for improving indoor air quality. The CONTAM simulation analysis of the MPA-space was performed by calculating the amount of $\mathrm{CO}_{2}$ generated per person per hour (g/s) for each activity. To calculate this, Equations (1)-(3) were utilized. The rate of increase in the $\mathrm{CO}_{2}$ generated per person per hour for an activity, the mole number of the $\mathrm{CO}_{2}$ generated per person per hour for an activity, and the amount of $\mathrm{CO}_{2}$ generated per person per hour for each activity were derived sequentially. First, using the experimental results for each activity, the rate of increase in the $\mathrm{CO}_{2}$ concentration generated per person per hour for each activity was calculated using Equation (1), which was proposed by $\mathrm{Cho}$ et al. [34,35].

The $\mathrm{CO}_{2}$ generation rate per person based on an activity can be expressed using Equation (1).

$$
\dot{C}_{\mathrm{CO}_{2}, P}=\frac{\left(C_{2}-C_{1}\right)}{\Delta t} V
$$

where

$\dot{C}_{\mathrm{CO}_{2}, P}$ is the amount of $\mathrm{CO}_{2}$ generated after the activity of one person per hour (ppm $\cdot \mathrm{m}^{3} / \mathrm{min}$ ).

$\mathrm{C}_{2}$ is the $\mathrm{CO}_{2}$ concentration at the end of the activity (ppm).

$C_{1}$ is the $\mathrm{CO}_{2}$ concentration at the beginning of the activity (ppm).

$V$ is the volume of the activity space volume $\left(\mathrm{m}^{3}\right)$. 
$\Delta t$ is the activity duration ( $\mathrm{min})$.

The number of moles of $\mathrm{CO}_{2}$ generated per person per hour for each activity was derived by multiplying the number of moles of air and $\mathrm{CO}_{2}$ by the rate of increase in the $\mathrm{CO}_{2}$ concentration per person per hour for each activity, as shown in Equation (2) [36-38].

The increase in the concentration of $\mathrm{CO}_{2}$ generated per person per hour for each activity can be calculated using Equation (2).

$$
\dot{n}_{\mathrm{CO}_{2}, P}=\dot{C}_{\mathrm{CO}_{2}, P} \frac{1}{V}{ }_{m}
$$

where

$\dot{n}_{\mathrm{CO}_{2}, \mathrm{P}}$ is the increase in moles of the $\mathrm{CO}_{2}$ generated by the activity of one person per hour $(\mathrm{kmol} / \mathrm{s})$.

$\dot{\mathrm{C}}_{\mathrm{CO}_{2}, \mathrm{P}}$ is the increase rate of the concentration of $\mathrm{CO}_{2}$ generated by the activity of one person per hour at a given volume $\left(\mathrm{ppm} \cdot \mathrm{m}^{3} / \mathrm{min}\right)$.

$V_{m}$ : The volume of 1 mole of an ideal gas in the standard state, $22.4 \mathrm{~L} / \mathrm{mol}$.

The number of moles of $\mathrm{CO}_{2}$ per hour for each activity was multiplied by the molecular weight to derive the "the amount of $\mathrm{CO}_{2}$ generated per person for each activity", as shown in Equation (3).

The increase in the $\mathrm{CO}_{2}$ concentration per hour per activity can be calculated using:

$$
\dot{m}_{\mathrm{CO}_{2}, P}=\dot{n}_{\mathrm{CO}_{2}, P} M_{\mathrm{CO}_{2}}
$$

where

$\dot{m}_{\mathrm{CO}_{2}, \mathrm{P}}$ is the amount of $\mathrm{CO}_{2}$ per person per hour for each activity $(\mathrm{g} / \mathrm{s})$.

$\dot{n}_{\mathrm{CO}_{2}, P}$ is the molar amount of $\mathrm{CO}_{2}$ generated per person per hour for each activity $(\mathrm{kmol} / \mathrm{s})$.

$M_{\mathrm{CO}_{2}}$ is the molecular weight of $\mathrm{CO}_{2}(\mathrm{~kg} / \mathrm{kmol})$.

Table 7 shows the amount of $\mathrm{CO}_{2}$ generated per person per hour for each activity in the MPA-space derived using the appropriate equation.

Table 7. $\mathrm{CO}_{2}$ generation per person per hour for each physical activity in D Elementary School.

Activity Type

Extracurricular Activities

Catch play (09:00 09:40)

Catch play (09:50 10:30)

Catch play (11:30 12:10)

Catch play (13:10 13:50)

After-school activity
Volume of $\mathrm{CO}_{2}$ Generated per Person (ppm. $\mathrm{m}^{3} / \mathrm{min} \cdot$ Person)

367.64

515.22

483.84

417.63

603.38

328.26
Mass of $\mathrm{CO}_{2}$ Generated per Person per Hour (g/s Person)

0.0120

0.0169

0.0158

0.0137

0.0198

0.0107

The amount of $\mathrm{CO}_{2}$ generated per person per hour during the stretching and catch activities, which require rapid movements and a large range of activity per person in the applicable space, was higher than that generated per person during club and after-school activities. In addition, the amount of $\mathrm{CO}_{2}$ generated per person during the same type of activity varied with a change in the duration of the activity, the change in temperature according to the duration, and before and after lunch time [14,39]. To verify the accuracy of the derived equation and determine the optimum number of occupants, the types of activities, and the area to be presented in the guidelines, the $\mathrm{CO}_{2}$ concentration was predicted using the CONTAM program.

The CONTAM simulation was performed as shown in Figure 6, based on the amount of $\mathrm{CO}_{2}$ generated per person per hour for each activity, the initial concentration analyzed in the ventilation and measurement experiments using the leakage area, the number of occupants, and the architectural factor information presented in Table 5 [40]. 


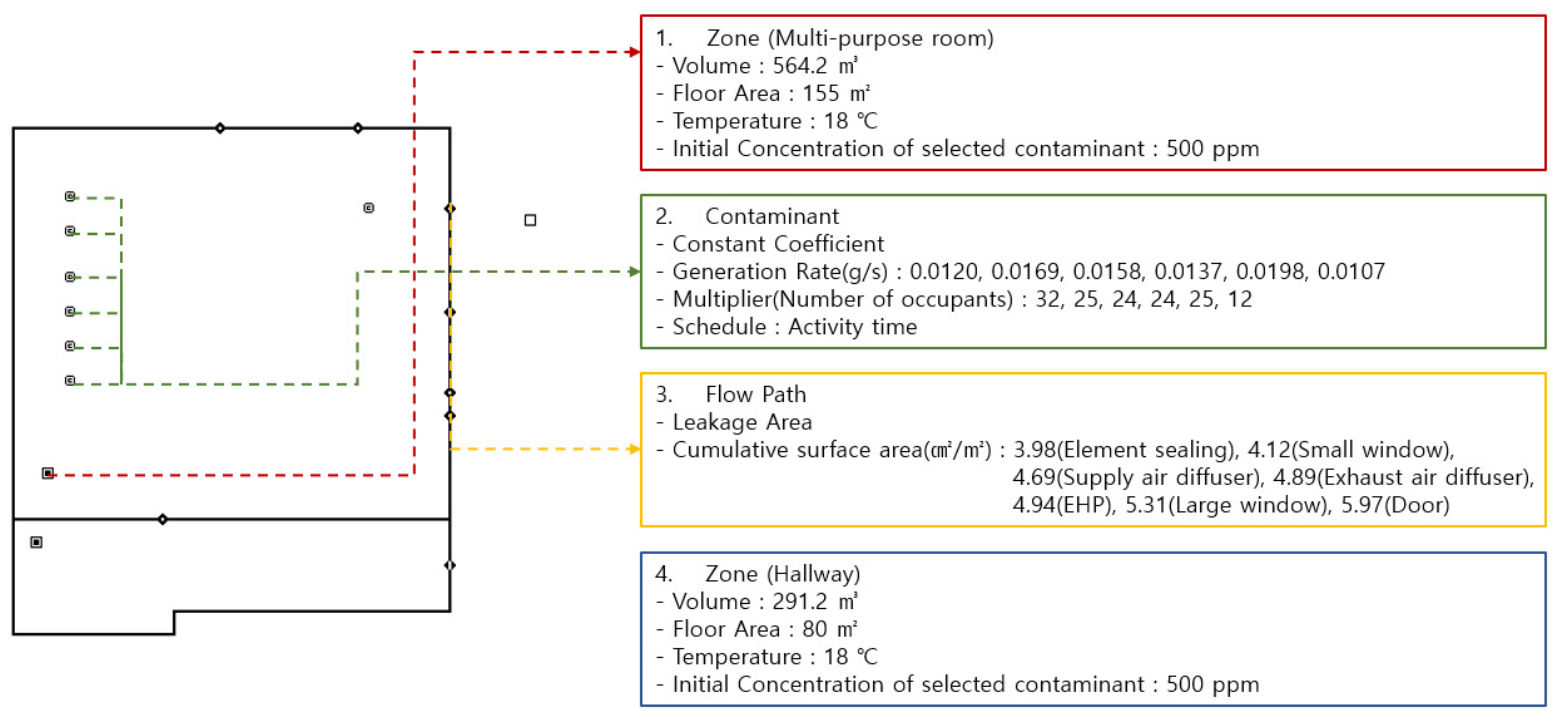

(a)

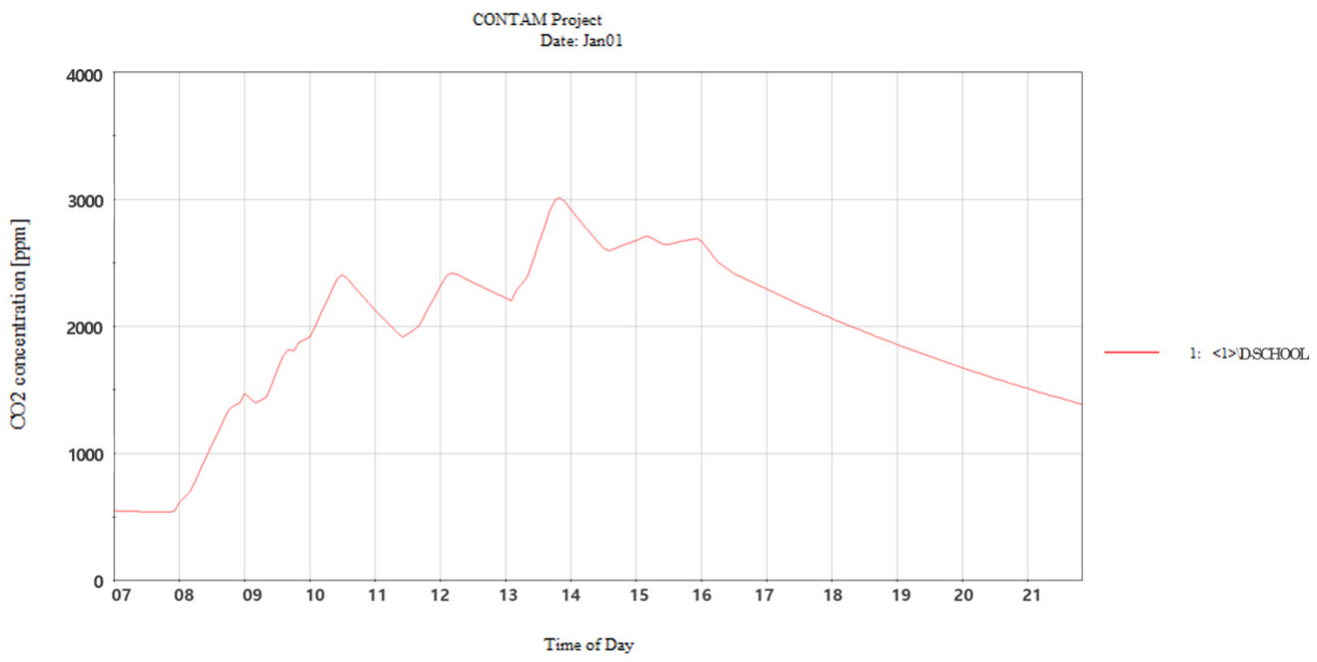

(b)

Figure 6. (a) Zone, pollutants, flow path, and corridor input conditions for the CONTAM simulation; (b) CONTAM simulation result of $\mathrm{CO}_{2}$ concentration.

To examine the effect of the facility volume on the $\mathrm{CO}_{2}$ generation, a CONTAM simulation was performed by applying the same occupant and activity conditions used in Case 1 to three different volumes. Case 1 was formulated by applying the architectural factors of the D elementary school, which were analyzed and compared to the actual measurement values. The accuracy of the CONTAM data applied to Case 1 was verified by calculating the RMSE of the square of the difference and MAPE [41]. The accuracy of the CONTAM data increased with a decrease in the RMSE [42-44]. MAPE refers to the percentage of the absolute error representing the accuracy of the simulation value in statistics [42]. The RMSE and MAPE were calculated using Equations (4) and (5), respectively:

where

$$
\begin{aligned}
\text { RMSE } & =\sqrt{\frac{1}{n} \sum_{i=1}^{n}\left(y_{i}-\hat{y}_{i}\right)^{2}} \\
\text { MAPE } & =\frac{100}{n} \sum_{i=1}^{n}\left|\frac{y_{i}-\hat{y}_{i}}{y_{i}}\right|
\end{aligned}
$$

RMSE is the Root mean square error (ppm).

MAPE is the Mean absolute percentage error (\%). 
$n$ is the number of data.

$y_{i}$ is the measured $\mathrm{CO}_{2}$ concentration (ppm).

$\hat{y}_{i}$ is the $\mathrm{CO}_{2}$ concentration estimated by the CONTAM simulation (ppm).

To verify the RMSE and MAPE results, the measured values and the CONTAM results were converted to five-minute unit data. The calculated RMSE was $123.37 \mathrm{ppm}$, and the RMSE-percent, which was calculated by dividing the percentage of the RMSE by the average concentration, was $6.02 \%$. The calculated MAPE was 5.50\%9 (Table 8), which is a relatively low error rate. In addition, A elementary school and $\mathrm{H}$ elementary school, which belong to the average of the architectural and facility factors in Table 1, were selected as Case 2 and Case 3, respectively, and the CONTAM simulation was performed [45].

Table 8. Root mean square error (RMSE) and mean accuracy percentage error (MAPE) of the CONTAM simulation results of the $\mathrm{CO}_{2}$ concentration in D Elementary School.

\begin{tabular}{ccc}
\hline RMSE (ppm) & RMSE-Percent (\%) & MAPE (\%) \\
\hline 123.37 & 6.02 & 5.50 \\
\hline
\end{tabular}

To increase the accuracy of the CONTAM simulation analysis, the experimental data measured every minute were converted to five-minute average data and plotted as shown in Figure 7.

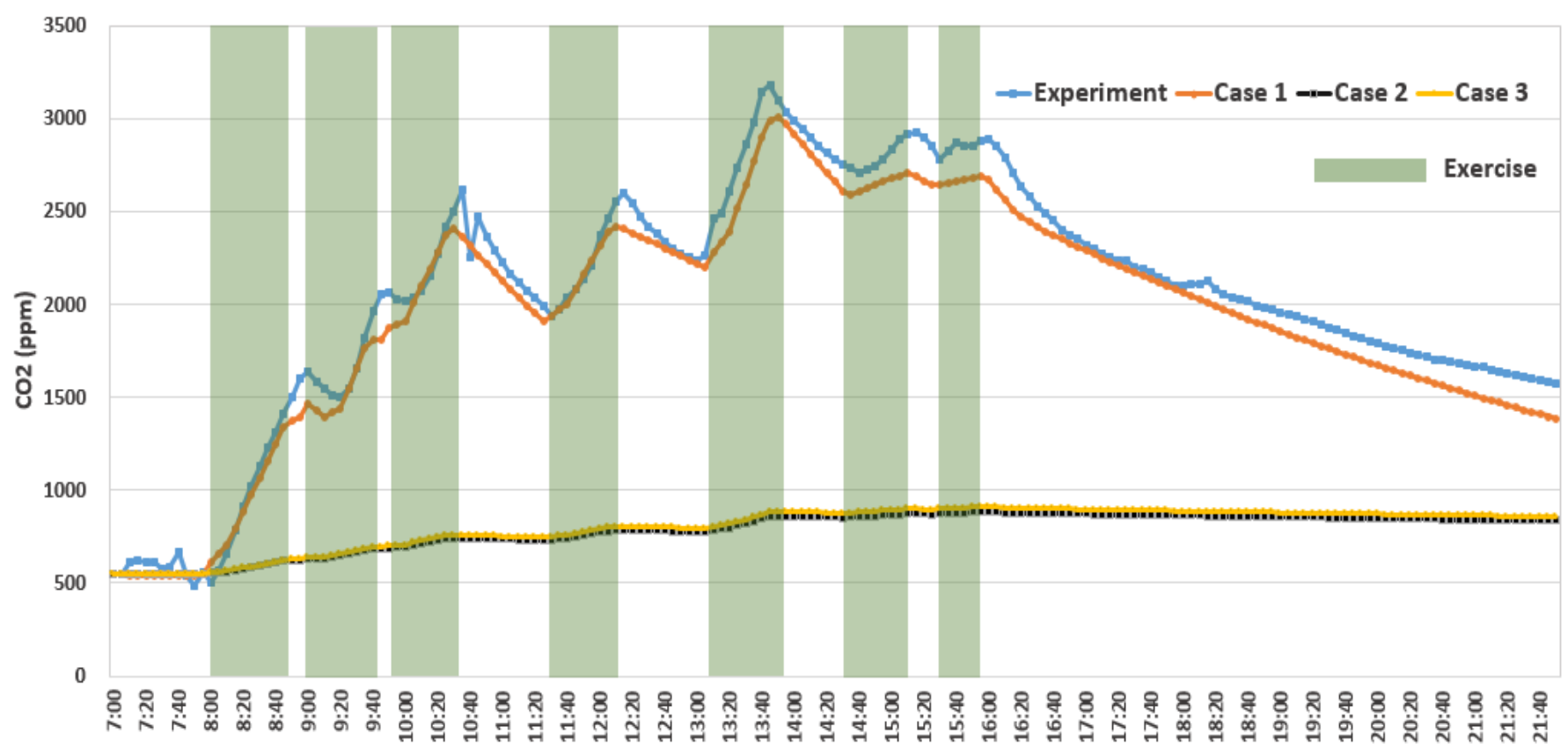

Figure 7. CONTAM simulation of the $\mathrm{CO}_{2}$ concentration of three cases, with similar conditions as that of the MPA-space of D elementary on 30 January.

The results revealed that the $\mathrm{CO}_{2}$ concentration gradient varied with a change in activity. The D elementary school with a Case 1 volume of $564.2 \mathrm{~m}^{3}$ exhibited a drastic change when the amount of $\mathrm{CO}_{2}$ for each activity was applied. Although the same leakage area of each element compared to the space volume was applied as the CONTAM simulation input condition for Cases 1,2, and 3, the natural reduction in $\mathrm{CO}_{2}$ concentration was higher in Case 1 than in Cases 2 and 3, which were large spaces containing stagnant air. [46-49].

In addition, the $\mathrm{CO}_{2}$ concentration in Cases 2 and 3 was maintained at concentrations below 1000 ppm, which is the standard concentration of the "Enforcement Rules of the Indoor Air Quality Control in Public-Use Facilities, Etc. Act [1]", after all activities and below $875 \mathrm{ppm}$ after 14:00 when the number of occupants was relatively low owing to after-school activities. 
To verify the reliability of the previously analyzed data, the indoor-air-quality measurement and CONTAM simulation analysis according to the activity were performed in the A elementary school (Case 2) with a large space.

\subsection{Verification of the Indoor Air Quality of the MPA-Space}

To verify the effect of the size of the facility on the properties of the indoor air quality of the facility for each activity, the indoor air quality of A elementary school was measured. The ultrafine-dust concentration and the $\mathrm{CO}_{2}$ concentration of A elementary school were measured using the same method used to calculate that of D elementary school. The floor area and ceiling height of the medium-sized MPA-space of A elementary school were $616.14 \mathrm{~m}^{2}$ and $10.4 \mathrm{~m}$, respectively. This facility was equipped with an EHP for heating and cooling, and a jet air turnover system was installed among the air purification systems; however, an air purifier that could directly improve fine dusts had not been installed. Thus, the characteristics of the indoor air quality of the MPA-space of A elementary school, which has a larger volume than D elementary school, were investigated using experimental analysis and CONTAM simulations [50,51]. Figure 8 shows an image of the experiment performed in the MPA-space of A elementary school on 18 November 2020 using the fine-dust sensor that was utilized in D elementary school. A 160 IAQ, which measures the indoor and outdoor $\mathrm{CO}_{2}$ concentration, was installed to consider the effect of the outdoor air. In addition, the concentration of ultrafine dusts was measured at points $\mathrm{A}$ and $\mathrm{B}$, at heights of 0.6 and $1.2 \mathrm{~m}$.

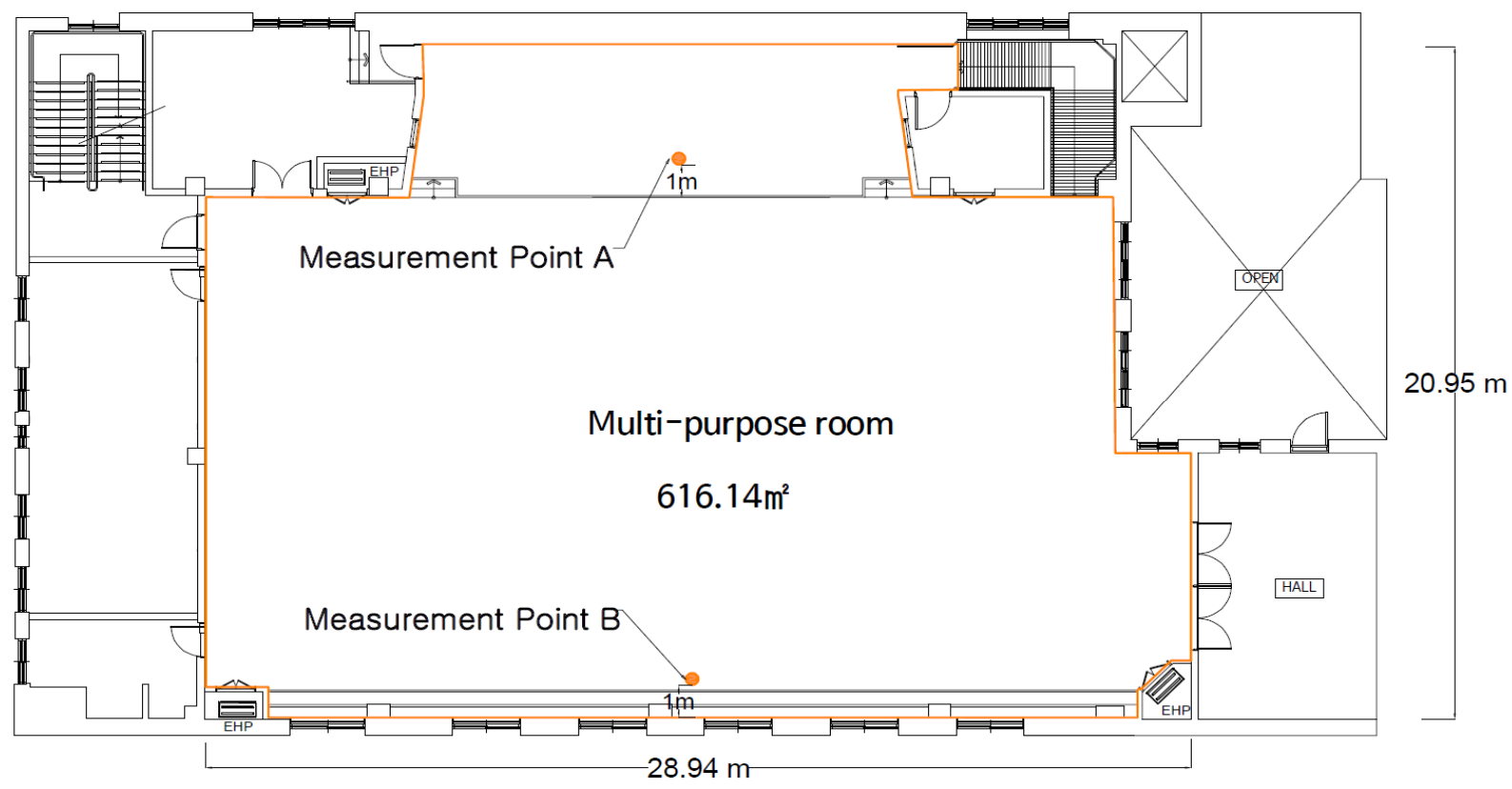

Figure 8. Floor plan of the MPA-space of A elementary school.

The results revealed that the number of occupants and the type of activities had no significant effect on the ultrafine-dust concentration of the MPA-space of A elementary school (Figure 9). In addition, the maximum ultrafine-dust concentration at points A and $B$ at a height of $1.2 \mathrm{~m}$ was $11.76 \mu \mathrm{g} / \mathrm{m}^{3}$, and the corresponding outdoor air concentration was $31.55 \mu \mathrm{g} / \mathrm{m}^{3}$. To analyze the effects of the activities of the occupants in a space on the concentration of fine dusts, additional measurements were obtained when the windows were opened and closed and when the doors were opened and closed [52-54]. Despite the increase in the concentration of ultrafine dusts in the outside air, the $\mathrm{CO}_{2}$ concentration in the MPA-space of A elementary school was maintained below $12 \mu \mathrm{g} / \mathrm{m}^{3}$ without any change in the concentrations of the ultrafine dusts. In contrast, there was a sharp increase in the $\mathrm{CO}_{2}$ concentration between 10:15 and 11:45 when the activity started (Figure 10). 


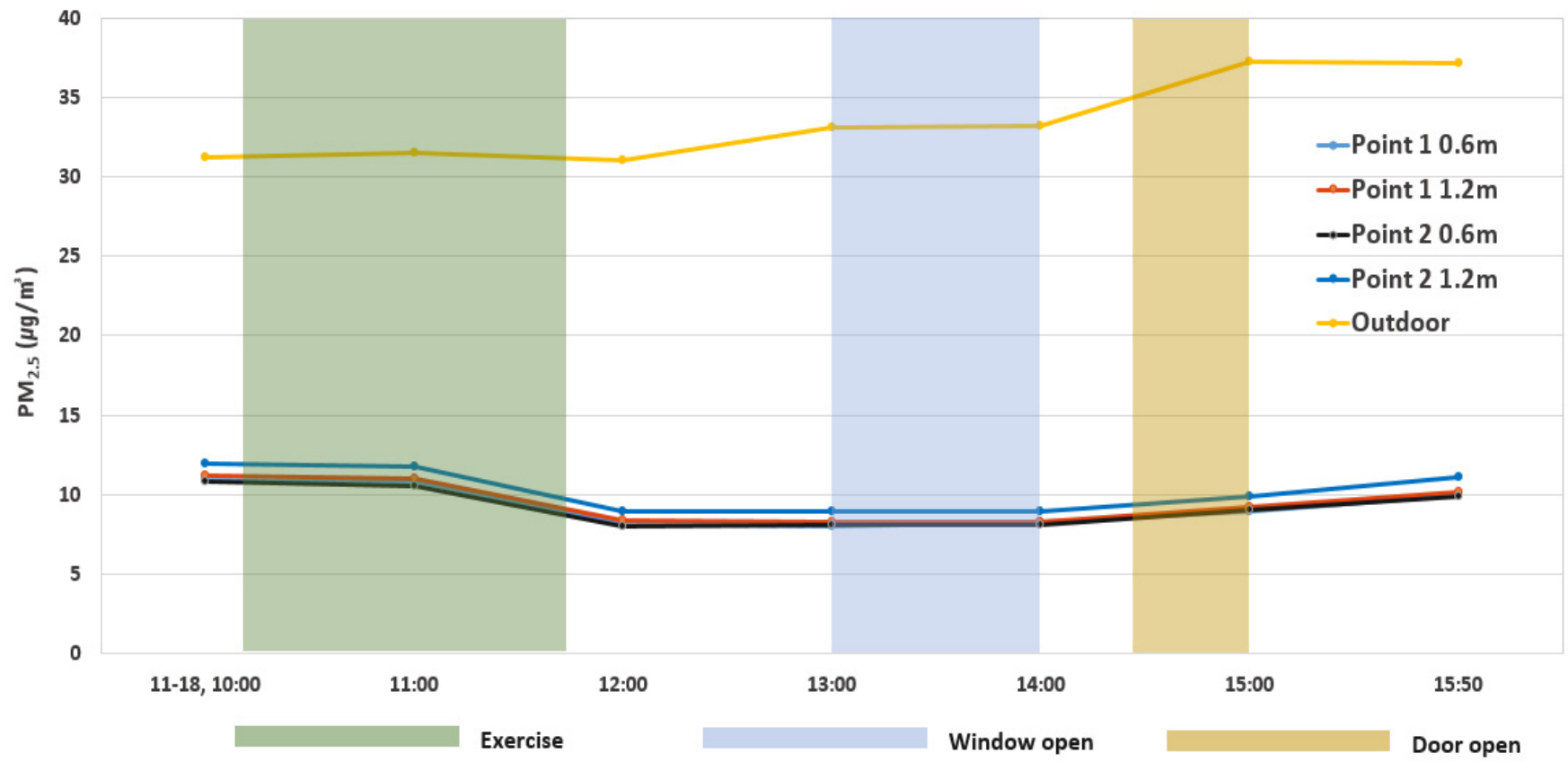

Figure 9. Measurement of the ultrafine-dust concentration (PM2.5) according to activities and window/door openings in the MPA-space of A elementary school on 18 November 2020.

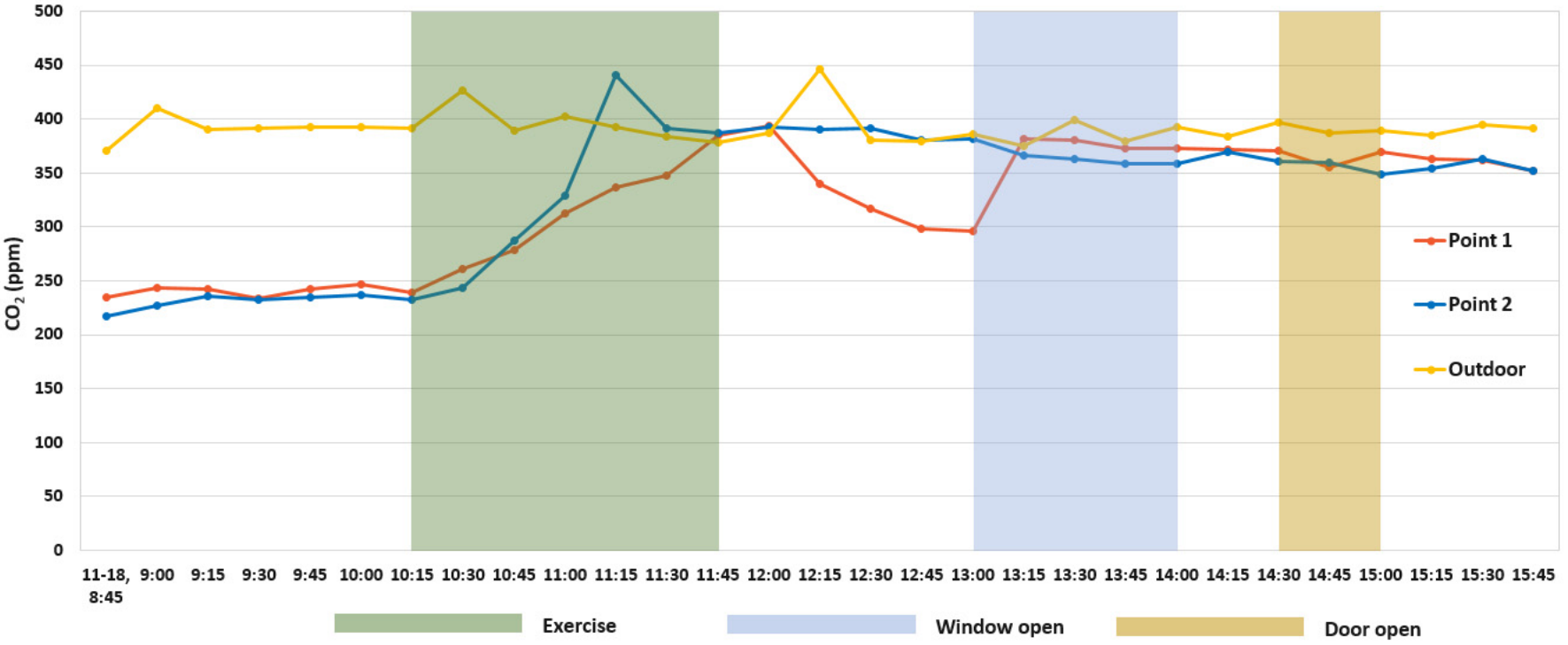

Figure 10. Change in the $\mathrm{CO}_{2}$ concentration as a function of physical activities and window / door openings in the MPA-space of A elementary school on 18 November 2020.

Furthermore, the measurement results of placing the $\mathrm{CO}_{2}$ concentration meter outdoors, and at points $\mathrm{A}$ and $\mathrm{B}$, revealed that the indoor $\mathrm{CO}_{2}$ concentration was approximately $200 \mathrm{ppm}$ lower than that of the outside air at the beginning of the activity (Figure 10). However, the $\mathrm{CO}_{2}$ concentration increased sharply from 10:15 am when 15 occupants started their activities and continued to increase to $441 \mathrm{ppm}$ (Table 9), which resulted in values similar to the outdoor $\mathrm{CO}_{2}$ concentration (Figure 10) $[55,56]$. The measured indoor $\mathrm{CO}_{2}$ concentration in A elementary school was maintained below the standard concentration of the "Enforcement Rules of the Indoor Air Quality Control in Public-Use Facilities, Etc. Act". To analyze the concentration of $\mathrm{CO}_{2}$ generated during each activity in A elementary school as a function of the facility volume, a CONTAM simulation of the $\mathrm{CO}_{2}$ concentration for each activity was performed. 
Table 9. Activity schedule of the MPA-space of A elementary school on 18 November 2020.

\begin{tabular}{cccc}
\hline Time & Activity Type & $\begin{array}{c}\text { Number of } \\
\text { Occupants }\end{array}$ & $\begin{array}{c}\text { Ventilation } \\
\text { before Activity }\end{array}$ \\
\hline 10:15-10:41 & Stretching, rope jump & 15 & $\mathrm{X}$ \\
10:42-11:45 & Badminton & 15 & $\mathrm{X}$ \\
13:00-14:00 & Window open & 2 & - \\
14:30-15:00 & Hallway door open & 2 & - \\
\hline
\end{tabular}

\subsection{Simulation Verification Analysis of the MPA-Space}

For the CONTAM simulation analysis of the MPA-space of A elementary school, the amount of $\mathrm{CO}_{2}$ generated per hour $(\mathrm{g} / \mathrm{s})$ per person per activity was calculated using Equation (3) (Table 10) [54]. The amount of $\mathrm{CO}_{2}$ generated per person per hour for each physical activity in the MPA-space of A elementary school was significantly higher than that generated in D elementary school (Table 10). Most of the students in A elementary school engaged in running-related physical activities, and their scope of activity was significantly wider than that of the students in the D elementary school, which can be attributed to the larger space of the MPA-space of A elementary school. The as-calculated amount of $\mathrm{CO}_{2}$ was utilized to perform the CONTAM simulation analysis by designating D, A, and $\mathrm{H}$ elementary schools as Cases 1, 2, and 3, respectively, as shown in Figure 11. The results revealed that the $\mathrm{CO}_{2}$ concentrations of Cases 2 and 3 were maintained below $430 \mathrm{ppm}$ with no notable change. In contrast, the $\mathrm{CO}_{2}$ concentrations of the D elementary school (Case 1) increased sharply to $2500 \mathrm{ppm}$ in $1 \mathrm{~h}$ and $30 \mathrm{~min}$ owing to its small volume [55,56].

Table 10. $\mathrm{CO}_{2}$ generation per person per hour for each physical activity in A Elementary school.

\begin{tabular}{ccc}
\hline Activity Type & $\begin{array}{c}\text { Rate of Increase in } \mathrm{CO}_{2} \text { Concentration per Person } \\
\left(\mathbf{p p m} \cdot \mathbf{~ m}^{3} / \mathbf{m i n}\right)\end{array}$ & $\begin{array}{c}\mathrm{CO}_{2} \text { Generation per Person } \\
(\mathrm{g} / \mathbf{s} \text { Person) }\end{array}$ \\
\hline Stretching, rope jump & 768.94 & 0.0252 \\
Badminton & 987.29 & 0.0323 \\
\hline
\end{tabular}

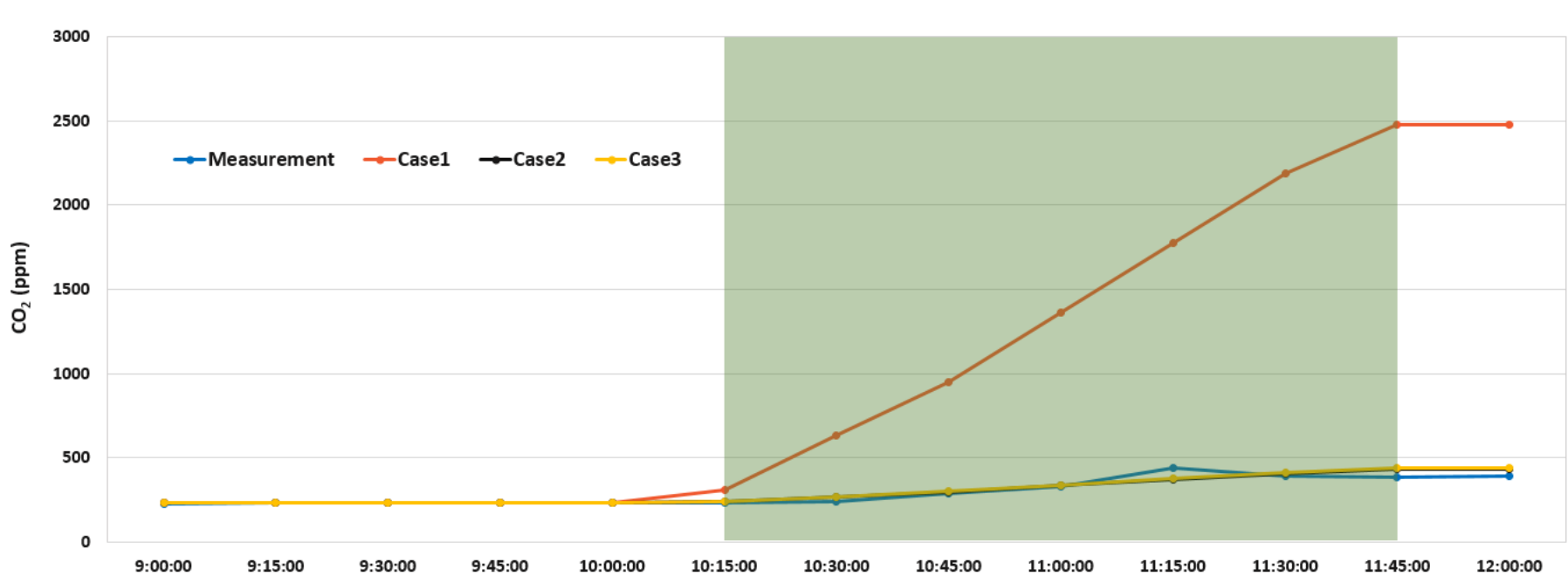

Figure 11. CONTAM Simulation of carbon dioxide concentration according to activity type in MPA-space in A elementary school.

The accuracy of the CONTAM simulation for the analysis of the $\mathrm{CO}_{2}$ concentration in A elementary school was verified using the same method used to verify that of D elementary school by calculating the RMSE and MAPE, and the results are shown in Table 11. The RMSE was $7.04 \mathrm{ppm}$, and the RMSE-percentage compared to the average concentration was $4.27 \%$. In addition, the MAPE was $2.37 \%$, which was a relatively low error rate. 
Table 11. RMSE and MAPE values of the CONTAM simulation of the $\mathrm{CO}_{2}$ concentration in $\mathrm{A}$ elementary school.

\begin{tabular}{ccc}
\hline RMSE & RMSE-Percent (\%) & MAPE (\%) \\
\hline 7.04 & 4.27 & 2.37 \\
\hline
\end{tabular}

The verification of the experimental results and the CONTAM simulation analysis revealed that despite the wide scope of activity and the high level of activities, the concentrations of both D and A elementary schools were maintained below $25 \mu \mathrm{g} / \mathrm{m}^{3}$, which is the standard value for the ultrafine-dust concentration prescribed by the WHO. In addition, the $\mathrm{CO}_{2}$ concentration of A elementary school, which has a larger volume than D elementary school, was maintained below the standard for the $\mathrm{CO}_{2}$ concentration prescribed by the "Enforcement Rules of the Indoor Air Quality Control in Public-Use Facilities, Etc. Act", which is currently enforced by the South Korean Government. Therefore, to maintain indoor air quality in an MPA-space with the high respiratory and activity levels of elementary school students, it is essential to determine the optimum number of occupants for a particular space size to maintain the $\mathrm{CO}_{2}$ concentration below the acceptable concentration, as well as the average required size per occupant for indoor physical education activities and the measures for reducing fine dusts [57].

\section{Measures against Increase in Indoor $\mathrm{CO}_{2}$ Concentration Due to Physical Education Activities}

Regardless of the measures currently implemented by the South Korean Government to reduce fine dusts, the indoor $\mathrm{CO}_{2}$ concentration negatively affected the indoor air quality of $\mathrm{A}$ and $\mathrm{D}$ elementary schools. To develop a strategy to maintain the indoor $\mathrm{CO}_{2}$ concentration, which exhibited a high concentration, below $1000 \mathrm{ppm}$, which is the domestic concentration limit prescribed by the "Enforcement Rules of the Indoor Air Quality Control in Public-Use Facilities, Etc. Act", this study proposed a guideline for maintaining the optimum average volume required per occupant during indoor physical education activities, as well as the optimum number of occupants per volume for each physical education activity [57-60].

\subsection{Optimum Volume per Occupant for Each Physical Eduction Activity}

The volume required per occupant for each activity to maintain the $\mathrm{CO}_{2}$ concentration below $1000 \mathrm{ppm}$ was derived based on the analysis of the amount of $\mathrm{CO}_{2}$ per person per hour for each physical activity using CONTAM simulation. The experimental data of $\mathrm{D}$ elementary school, including leakage area, initial indoor $\mathrm{CO}_{2}$ concentration, and initial indoor temperature, were utilized $[57,59,60]$.

The results revealed that the minimum required volume for badminton activities was approximately $133 \mathrm{~m}^{3}$, and the average required volume per person for each activity was approximately $88 \mathrm{~m}^{3}$ (Table 12). Thus, based on the class presented in Table 2, if 35 students engage in an average physical education activity for $1 \mathrm{~h}$, the space must be at least $3080 \mathrm{~m}^{3}$ to maintain the indoor $\mathrm{CO}_{2}$ concentration below $1000 \mathrm{ppm}$.

Table 12. Required volume per occupant based on the activities.

\begin{tabular}{|c|c|c|c|c|}
\hline $\begin{array}{l}\text { Classification } \\
\text { of Activities }\end{array}$ & $\begin{array}{c}\mathrm{CO}_{2} \text { Generation Rate } \\
\text { per Person }(\mathrm{g} / \mathrm{s} \cdot \text { Person) }\end{array}$ & Initial Temperature $\left({ }^{\circ} \mathrm{C}\right)$ & $\begin{array}{c}\text { Initial } \mathrm{CO}_{2} \\
\text { Concentration (ppm) }\end{array}$ & $\begin{array}{l}\text { Required Volume } \\
\left(\mathrm{m}^{3} / \text { Hour } \cdot \text { Person) }\right.\end{array}$ \\
\hline Extracurricular activities (a) & 0.0120 & & & 48.5 \\
\hline Stretching and catch play (b) & 0.0166 & & & 67.5 \\
\hline Stretching and rope jump (c) & 0.0252 & 18 & 520 & 102.5 \\
\hline Badminton (d) & 0.0323 & & & 132.5 \\
\hline Average & 0.0215 & & & 87.8 \\
\hline
\end{tabular}




\subsection{Determination of the Optimum Number of Occupants for an MPA-Space}

To analyze the optimum number of occupants required to maintain the $\mathrm{CO}_{2}$ concentration below $1000 \mathrm{ppm}$ for each physical activity, the as-calculated required volume per person for each activity was divided by the volume of MPA-space of D elementary school $\left(564.2 \mathrm{~m}^{3}\right)$, and the results are shown in Table 13.

Table 13. Optimum number of students according to activities for D and A Elementary Schools.

\begin{tabular}{ccc}
\hline Elementary School & Activity & Optimum Number of Students \\
\hline & Extracurricular activities & 12 \\
D & Stretching and catch & 8 \\
& Stretching and rope jump & 5 \\
& Badminton & 4 \\
& Extracurricular activities & 130 \\
A & Stretching and catch & 94 \\
& Stretching and rope jump & 62 \\
& Badminton & 48 \\
\hline
\end{tabular}

The optimum number of occupants required to maintain the $\mathrm{CO}_{2}$ concentration below $1000 \mathrm{ppm}$ in the MPA-space of D elementary school, assuming that they were engaged in physical education, was analyzed $[57,59,60]$. The results revealed that the optimum number of occupants required to maintain the $\mathrm{CO}_{2}$ concentration in the MPA-space of D elementary school below 1000 ppm was 4-12, depending on the activities, which is significantly lower than that of the experimental results. In contrast, the optimum number of occupants required to maintain the $\mathrm{CO}_{2}$ concentration in the MPA-space of A elementary school below $1000 \mathrm{ppm}$ ranged from 48 to 130 , which significantly exceeded the experimental results.

The results of the required volume per person and the optimum number of occupants for each activity required to maintain the indoor $\mathrm{CO}_{2}$ concentration during physical education activities below harmful levels indicate that it is essential to reduce the number of occupants for each activity, depending on the size of the MPA-space, in elementary schools. In situations where the number of occupants for each activity in one class exceeds the optimum number, mechanical ventilation is required.

A correlation Equation (6) was derived based on the required volume per occupant and the optimum number of occupants for each physical education activity and was presented in Sections 5.1 and 5.2. If the amount of indoor $\mathrm{CO}_{2}$ per person per hour for each activity (Tables 7 and 10) is applied to this Equation, the appropriate activity type, the optimum number of occupants, and the activity duration that can maintain indoor air quality below harmful levels can be calculated for a given volume.

$$
\mathrm{C}_{\mathrm{CO}_{2}}=\mathrm{C}_{\mathrm{CO}_{2}, i}+\frac{\dot{\mathrm{C}}_{\mathrm{CO}_{2}, \mathrm{P}} n t}{V} \leq 1000 \mathrm{ppm}
$$

where

$\mathrm{C}_{\mathrm{CO}_{2}}$ is the indoor $\mathrm{CO}_{2}$ concentration for activities (ppm).

$\mathrm{C}_{\mathrm{CO}_{2}, i}$ is the initial indoor $\mathrm{CO}_{2}$ concentration (ppm).

$\dot{C}_{\mathrm{CO}_{2}, P}$ is the amount of $\mathrm{CO}_{2}$ per hour by one person's activity (Tables 7 and 10) (ppm $\cdot \mathrm{m}^{3} / \mathrm{min}$ ).

$n$ is the number of occupants.

$V$ is the space volume $\left(\mathrm{m}^{3}\right)$.

$t$ is the activity duration ( $\mathrm{min})$.

Using the correlation Equation (6), the average number of students per class in each school was applied to A and D elementary schools, which exhibited the smallest facility volumes, as shown in Figure 1, and the results of applying the badminton activities shown in Table 10 were calculated, as listed in Table 14. 
Table 14. $\mathrm{CO}_{2}$ concentration during badminton activities for $1 \mathrm{~h}$ in elementary school $\mathrm{A}$ and $\mathrm{D}$, calculated using Equation (6).

\begin{tabular}{|c|c|c|c|c|c|c|}
\hline $\begin{array}{l}\text { Name of } \\
\text { School }\end{array}$ & $\begin{array}{c}\text { Initial } \mathrm{CO}_{2} \\
\text { Concentration } \\
(\mathrm{ppm})\end{array}$ & $\begin{array}{l}\text { Rate of Increase in } \mathrm{CO}_{2} \\
\text { Concentration per Person } \\
\left(\mathrm{ppm} \cdot \mathrm{m}^{3} / \mathrm{min}\right)\end{array}$ & $\begin{array}{l}\text { Time } \\
(\min )\end{array}$ & $\begin{array}{c}\text { Number of } \\
\text { Classes }\end{array}$ & $\begin{array}{l}\text { Space } \\
\text { Volume } \\
\left(\mathrm{m}^{3}\right)\end{array}$ & $\begin{array}{c}\text { Result } \\
\text { (ppm) }\end{array}$ \\
\hline A & 520 & 987.29 & 60 & 28 & 6407.9 & 778.84 \\
\hline D & $3 \angle 0$ & & 60 & 25 & 564.2 & 3144.84 \\
\hline
\end{tabular}

The change in the $\mathrm{CO}_{2}$ concentration during badminton activities in $\mathrm{A}$ and $\mathrm{D}$ elementary schools (Table 10) and the optimum number of occupants required to maintain the $\mathrm{CO}_{2}$ concentration below harmful levels (Table 13) were applied to Equation (6), and the results are shown in Table 15.

Table 15. $\mathrm{CO}_{2}$ concentration generated by the optimum number of students in elementary school A and D during badminton activities calculated using Equation (6).

\begin{tabular}{ccccccc}
\hline $\begin{array}{c}\text { Name of } \\
\text { School }\end{array}$ & $\begin{array}{c}\text { Initial } \mathrm{CO}_{\mathbf{2}} \\
\text { Concentration } \\
(\mathbf{p p m})\end{array}$ & $\begin{array}{c}\text { Rate of Increase in } \mathrm{CO}_{2} \\
\text { Concentration per Person } \\
\left(\mathbf{p p m} \cdot \mathbf{m}^{\mathbf{3}} / \mathbf{m i n}\right)\end{array}$ & $\begin{array}{c}\text { Time } \\
(\mathbf{m i n})\end{array}$ & $\begin{array}{c}\text { Number of } \\
\text { Classes }\end{array}$ & $\begin{array}{c}\text { Space } \\
\text { Volume } \\
\left(\mathbf{m}^{\mathbf{3}}\right)\end{array}$ & $\begin{array}{c}\text { Result } \\
(\mathbf{p p m})\end{array}$ \\
\hline $\mathrm{A}$ & 520 & 987.29 & 60 & 48 & 6407.9 & 963.73 \\
$\mathrm{D}$ & & & 4 & 564.2 & 939.97 \\
\hline
\end{tabular}

The formula and guidelines can be used for both new and existing school buildings. First, when designing a new school building, the volume size and the HVAC facilities can be determined for target student numbers and activities. This will prevent excessive design of space and mechanical ventilation facilities. Second, in the case of existing school buildings, a physical education teacher or person in charge can use it to calculate the number of students and the hours of activity. For example, if the "indoor $\mathrm{CO}_{2}$ concentration for activities" calculated through Equation (6) exceeds 1000 ppm according to the guidelines, the number of people allocated per class can be reduced and the physical education classes can be adjusted.

\section{Discussion}

The guidelines and correlation equations developed in this study can be applied in both new and existing school buildings. First of all, in the case of new school buildings, the $\mathrm{CO}_{2}$ concentration can be predicted using Equation (6) for sports activities and occupants, and the carbon dioxide generation according to the carbon dioxide prediction equations. This correlation reflects the effect of the space volume and mechanical ventilation facilities. In the case of existing school buildings, a total of four representative sports activities have been presented in Table 12 so that non-experts can use them without indoor-air-quality experiments to predict the indoor carbon dioxide concentration according to the number of people and the activity time.

However, in the case of the Multi-purpose activity spaces of schools in Korea, unlike general classrooms, the volume sizes are very diverse; so, it was difficult to present standard models in this study. Thus, actual data, including volume size, must be directly substituted into the correlation formula. In addition, the further limitations of this study are that the air exchange rate according to the aging effect of the building and the location of various mechanical ventilation facilities were not considered.

Therefore, in future studies, it is necessary to present a standard model according to the size of the space, to consider the number of years in use, and to conduct additional analysis according to the location of mechanical ventilation facilities. 


\section{Conclusions}

This study analyzed the air quality of the MPA-space in elementary schools and derived a correlation equation for the type of activity, the number of occupants, and the duration of the activity, which satisfies the indoor air quality requirement for a given volume. In addition, the average characteristics of the indoor air pollutants were identified by analyzing the architectural and equipment factors of the MPA-space in nine elementary schools. The conclusions obtained in this study are as follows.

(1) The characteristics of the indoor air pollutants in the indoor MPA-space were identified, and the increase in the quantity of these pollutants as a function of the physical education activity was characterized.

(2) The amount of $\mathrm{CO}_{2}$ generated per elementary school student per hour ranged from 0.0120 to $0.0323 \mathrm{~g} / \mathrm{s}$. In addition, the average space volume required per person at an initial indoor $\mathrm{CO}_{2}$ concentration of $520 \mathrm{ppm}$ was approximately $88 \mathrm{~m}^{3} / \mathrm{h} \cdot$ person for a one-hour physical activity. Furthermore, the optimum volume required by 35 elementary school students engaging in physical activities for an hour to maintain the indoor $\mathrm{CO}_{2}$ concentration below $1000 \mathrm{ppm}$ was $3080 \mathrm{~m}^{3}$.

(3) A correlation equation for the required volume per person for each activity was derived using the analysis of the amount of $\mathrm{CO}_{2}$ per person per hour for each activity, and a guideline was presented based on this result.

(4) The required volume of the MPA-space was determined based on the predetermined optimum number of occupants, and a guideline for design purposes was presented.

(5) A correlation formula was provided to help physical education teachers identify the characteristics of indoor air pollutants during physical education activities and conduct physical education classes.

In future research, we intend to present a standard model for the volume of the MPA-space in elementary schools and calculate the concentration of indoor air pollutant generated during various physical education activities. Further research will investigate the appropriate location and number of machine ventilation systems and air purification facilities.

Author Contributions: Conceptualization, Y.-K.L.; methodology, Y.-K.L.; experiment, Y.-K.L.; software, Y.-K.L.; validation, Y.I.K.; formal analysis, Y.-K.L.; investigation, Y.-K.L.; resources, Y.-K.L.; data curation, Y.-K.L.; writing—original draft preparation, Y.-K.L.; writing—review and editing, Y.I.K.; visualization, Y.-K.L.; supervision, Y.I.K.; project administration, Y.I.K.; funding acquisition, Y.I.K. All authors have read and agreed to the published version of the manuscript.

Funding: This work was supported by the National Research Foundation of Korea (NRF) grant, funded by the Korean Government (Ministry of Science, Technology, and Innovation; Ministry of Education). (No.2019M3E7A1113095).

Institutional Review Board Statement: Informed consent was obtained from all subjects involved in the study. The study neither interfered with nor controlled physical activity.

Conflicts of Interest: The authors declare no conflict of interest.

\section{References}

1. Kang, D.M.; Kim, J.E. Fine, Ultrafine, and Yellow Dust: Emerging Health Problems in Korea. J. Korean Med. Sci. 2014, 29, 621-622. [CrossRef]

2. Korea Ministry of Environment. Enforcement Rules of the Domestic Indoor Air Quality Management Act; Ministry of Environment Ordinance No. 918; Annex 2 Maintenance Standards; Korea Ministry of Environment: Seoul, Korea, 2021.

3. Fine Dust Data by Year in China. Available online: https://aqicn.org/city/hongkong/kr (accessed on 1 August 2021).

4. National Institute of Environmental Research. 2019 Air Environment Annual Report; Korea Environment Corporation: Sejong, Korea, 2020.

5. IQAir AirVisual. 2019 World Air Quality Report; IQAir: Goldach, Switzerland, 2020.

6. Myung, H.-N. 2017 Fine Dust and Health in Our Region; Open Chungnam: Chungnam, Korea, 2017; Volume 79, pp. 13-17.

7. Fine Dust Alert Status Report; Chungnam Institute of Health and Environment: Chungnam, Korea, 2017. 
8. Jung, S.-K.; Jun, K.-W. A Study on the Health Vulnerability Assessment of Particle Matter in Incheon. J. Korean Soc. Hazard Mitig. 2020, 20, 31-40. [CrossRef]

9. Kim, S.-A.; Park, J.-H.; Han, D.-Y.; Chung, I.-J. The Effects of Fine Dust on Children's Health: The Moderating Effects of Poverty and Green Area Ratio. J. Korean Soc. Hazard Mitig. 2020, 20, 163-171. [CrossRef]

10. Ministry of Environment. High-Concentration Fine Dust Response Manual for the Protection of Vulnerable Groups such as Children, Students, and Senior Citizens; Ministry of Environment: Sejong, Korea, 2016; p. 2.

11. Bennett, W.D.; Zeman, K.L.; Jarabek, A.M. Nasal Contribution to Breathing and Fine Particle Deposition in Children versus Adults. J. Toxicol. Environ. Health 2008, 71, 227-237. [CrossRef]

12. Bateson, T.F.; Schwartz, J. Children's Response to Air Pollutants. J. Toxicol. Environ. Health 2008, 71, 238-343. [CrossRef] [PubMed]

13. Jang, N.-R.; Lee, S.-W. A Study on Elementary School Students Knowledge-Awareness and Attitude toward Fine Dust. J. Korean Pract. Arts Educ. 2020, 33, 1-20. [CrossRef]

14. Lee, B.-S.; Park, J.-K. Comparison about Time Serial Change of Carbon Dioxide's Concentration and Ventilation at Apartment Room. J. Korea Soc. Environ. Adm. 2006, 12, 27-36.

15. Park, Y.-J.; Kim, Y.-J. Study on the Perception of Indoor Air Quality in a Dance Education Space. Korean J. Danc. 2019, 19, 71-82. [CrossRef]

16. Yu, S.; HE, L.; Feng, G. The Transient Simulation of Carbon Dioxide Emission from Human Body Based on Contam. Procedia Eng. 2015, 121, 1613-1619. [CrossRef]

17. Lim, S.-G.; Kim, J.-H.; Kim, T.-H.; Lee, K.-Y.; Yang, W.-H.; Jung, S.-G.; Yu, S.-D. Personal exposures to PM 2.5 and their relationships with microenvironmental concentrations. Atmos. Environ. 2012, 47, 407-412. [CrossRef]

18. Seoul Metropolitan Office of Education. 2019 Seoul Metropolitan Office of Education Working Manual for High Concentration Fine Dust Response; Seoul Metropolitan Office of Education: Seoul, Korea, 2019.

19. Park, H.-S.; Kim, M.-S.; Kim, S.-H.; Ma, R.-W.; Kim, M.-S. The Influence of Awareness regarding Particulate Matter, Perceived Respiratory Symptoms, and Physical Activities on Health Promotion Behavior of Elementary School Children. J. Korean Acad. Fundam. Nurs. 2020, 27, 95-105. [CrossRef]

20. Lee, S.-M. A qualitative case study on physical education classes for efforts to overcome fine dust. J. Korean Soc. Study Phys. Educ. 2019, 8, 73-88.

21. National School Information, Number of Students. Available online: https:/ / www.schoolinfo.go.kr/ (accessed on 1 August 2021)

22. Korean Institute of Educational Environment. Academic Research on School Facility Plan Design Guidelines and Facility Standards Development; Metropolitan Office of Education: Seoul, Korea, 2013.

23. Building Plan Data, Elementary/Secondary School Planning and Design Materials. Available online: https://www.archidata.co. $\mathrm{kr} /$ (accessed on 1 August 2021).

24. Lee, C.-W.; Suh, K.-W.; Kang, Y.-J.; Kim, D.-W.; Jo, M.-T. Investigation of Jet Air Turnover System Using a Numerical Method. In Proceedings of the 2014 SAREK Summer Annual Conference, Pyeongchang, Korea, 25-27 June 2014; pp. 557-562.

25. Information on Waiting around Our School, Measurement Data Inquiry. Available online: https: / / www.airkorea.or.kr/web/ realschoolSearch (accessed on 1 August 2021).

26. Department of the Environment. Enforcement Rules of the Indoor Air Quality Control Act; Ministry of Environment Decree: Seoul, Korea, 2020; p. 858.

27. Yun, J.-U. Experiment and Analysis of Ventilation Rate for Maintaining $\mathrm{CO}_{2}$ Concentration in School Buildings. Master's Thesis, Seoul National University of Science and Technology, Seoul, Korea, 2019.

28. Turanjanin, V.; Vučićević, B.; Jovanović, M.; Mirkov, N.; Lazović, I. Indoor $\mathrm{CO}_{2}$ Measurements in Serbian Schools and Ventilation Rate Calculation. Energy 2014, 77, 290-296. [CrossRef]

29. Undram, M.-C.; Song, D.-S.; Kim, J.-W. A Review of the Test Methods for Air-tightness Performance of Building Components Using the Blower Door System. Korea J. Air-Cond. Refrig. Eng. 2019, 31, 216-226.

30. ASHRAE. 2017 ASHRAE Handbook Fundamentals; ASHRAE: Atlanta, GA, USA, 2017.

31. Hering, S.V.; Lunden, M.M.; Thatcher, T.L.; Kirchstetter, T.W.; Brown, N.J. Using Regional Data and Building Leakage to Assess Indoor Concentrations of Particles of Outdoor Origin. Aerosol. Sci. Technol. 2007, 41, 639-654. [CrossRef]

32. Lee, Y.G.; Shin, C.W. The Air Leakage Characteristics and Airtightness Performance of a Newly Built Apartment. Korean J. Air-Cond. Refrig. Eng. 2013, 25, 606-611.

33. Kim, M.S.; Auh, J.S.; Hong, G.P.; Kim, B.S. Analysis on Ventilation Performance of Natural Ventilation Systems in Multi-Family Housing Using Blower Door Test. Korea Inst. Ecol. Archit. Environ. 2016, 16, 129-134.

34. Cho, Y.-M.; Lee, J.-Y.; Kwon, S.-P.; Park, D.-S.; Park, J.-H.; Cho, K.-C. The Distribution Characteristics of Carbon Dioxide in Indoor School Spaces. J. Korean Soc. Atmos. Environ. 2011, 27, 117-125. [CrossRef]

35. Kapalo, P.; Vilcekova, S.; Voznyak, O. Using Experimental Measurements of the Concentrations of Carbon Dioxide for Determining the Intensity of Ventilation in the Rooms. Chem. Eng. Trans. 2014, 39, 1789-1794.

36. So, J.S.; Yoo, S.Y. A Prediction of $\mathrm{CO}_{2}$ Concentration and Measurement of Indoor Air Quality in the EMU. J. Korean Soc. Railw. 2008, 11, 378-383.

37. Shafie, N.E.A.; Kamar, H.M.; Kamsah, N. Effects of Air Supply Diffusers and Air Return Grilles Layout on Contaminants Concentration in Bus Passenger Compartment. Int. J. Automot. Technol. 2016, 17, 751-762. [CrossRef] 
38. Jeong, J.H.; Roh, J.Y.; Lee, H.S.; Jeon, E.C. Development of Non- $\mathrm{CO}_{2}$ Emission Factor of Wood Chip Fired Fluidized Bed Combustion. J. Clim. Chang. Res. 2019, 10, 221-226. [CrossRef]

39. Kim, J.-E.; Han, J.-S.; Kim, Y.-G.; Han, J.-W.; Yang, J.-Y.; Park, Y.-S.; Yi, S.-H. Trends Analysis of Carbon Dioxide Concentration Changes in Classroom. In Proceedings of the 2012 KIGAS Autumn Conference, Gangneug, Korea, 23 November 2012 ; p. 125.

40. Stuart Dols, W.; Polidoro, B.J. Contam User Guide and Program Documentation, Version 3.2.; NIST: Gaithersburg, MD, USA, 2015.

41. So, M.-S.; Shin, J.-H. Performance Degradation Prediction of Industrial Equipment using Machine Learning. Korean J. Comput. Des. Eng. 2019, 24, 268-279. [CrossRef]

42. Shin, K.-J.; Kim, H.-J.; Cho, Y.-H. A study of the Prediction Model of Indoor Carbon Dioxide Concentrations. J. Korean Inst. Archit. Sustain. Environ. Build. Syst. 2016, 10, 83-89.

43. Hong, T.-H.; Kim, H.-P.; Kim, J.-M.; An, J.-B.; Kang, H.-A.; Hong, J.-W.; Yeom, S.-K. Development of the Indoor fine dust density forecast model using Long Short Term Memory. In Proceedings of the 2018 Korea Society of Energy \& Climate Change Conference, Jeju, Korea, 28 November 2018; Volume 11, p. 185.

44. Kim, S.-H.; Han, G.-T. A Study of Indoor Air Pollution Prediction based on LSTM Model using Fine Dust Sensor Data in Kitchen Environment. In Proceedings of the Symposium of the Korean Institute of communications and Information Sciences, Seoul, Korea, 5 February 2020; pp. 1127-1128.

45. Buonanno, G.; Fuoco, F.C.; Morawska, L.; Stabile, L. Airborne particle concentrations at schools measured at different spatial scales. Atmos. Environ. 2013, 67, 38-45. [CrossRef]

46. Alves, C.A.; Calvo, A.I.; Castro, A.; Fraile, R.; Evtyugina, M.; Bate-Epey, E.F. Indoor Air Quality in Two University Sports Facilities. Aerosol Air Qual. Res. 2013, 13, 1723-1730. [CrossRef]

47. Dutton, S.; Shao, L.; Riffat, S. Validation and Parametric Analysis of EnergyPlus: Air Flow Network Model Using CONTAM. In Proceedings of the Third National Conference of IBPSA, Berkeley, CA, USA, 30 July-1 August 2008; pp. 124-131.

48. Wang, Z.; Hu, Y.; Jiang, J. Numerical investigation of leaking and dispersion of carbon dioxide indoor under ventilation condition. Energy Build. 2013, 66, 461-466. [CrossRef]

49. Khatami, N.; Cook, M.J.; Firth, S.K.; Hudleston, N. Control of carbon dioxide concentration in educational spaces using natural ventilation. Int. J. Vent. 2013, 11, 339-352. [CrossRef]

50. Song, K.-D. The Research Issues and Recent Activities in HVAC Design for Large Enclosures; The Society of Air-Conditioning and Refrigerating Engineers of Korea: Seoul, Korea, November 1997; Volume 11, pp. 3-20.

51. Seo, M.-S.; Jung, S.-H.; Park, C.-S.; Kim, Y.-T.; Cho, J.-S. HVAC Design and construction procedures in the large enclosures. In Proceedings of the 2013 SAREK Summer Conference, Yongpyong, Korea, 20-22 December 2013; pp. 667-672.

52. Teleszewski, T.; Gładyszewska-Fiedoruk, K. Changes of Carbon Dioxide Concentrations in Classrooms: Simplified Model and Experimental Verification. Pol. J. Environ. Stud. 2018, 27, 2397-2409. [CrossRef]

53. Darus, F.M.; Nasir, R.A.; Sumari, S.M.; Ismail, Z.S.; Omar, N.A. Heavy Metals Composition of Indoor Dust in Nursery Schools Building. Soc. Behav. Sci. 2012, 38, 169-175. [CrossRef]

54. McGrath, J.A.; Byrne, M.A.; Ashmore, M.R.; Terry, A.C.; Dimitroulopoulou, C. A simulation study of the changes in PM2.5 concentrations due to interzonal airflow variations caused by internal door opening patterns. Atmos. Environ. 2014, 87, 183-188. [CrossRef]

55. Kapalo, P.; Mečiarová, L'.; Vilčeková, S.; Burdová, E.K.; Domnita, F.; Bacotiu, C.; Péterfi, K.E. Investigation of $\mathrm{CO}_{2}$ production depending on physical activity of students. Int. J. Environ. Health Res. 2019, 29, 31-44. [CrossRef] [PubMed]

56. Tsega, E.G.; Katiyar, V.K.; Gupta, P. Breathing Patterns of Healthy Human Response to Different Levels of Physical Activity. J. Biomed. Eng. Technol. 2019, 7, 1-4. [CrossRef]

57. Kapalo, P.; Domniţa, F.; Bacoţiu, C.; Spodyniuk, N. The Impact of Carbon Dioxide Concentration on the Human Health-Case Study. J. Appl. Eng. Sci. 2018, 8, 61-66. [CrossRef]

58. Al-Rashidi, K.; Loveday, D.; Al-Mutawa, N. Impact of ventilation modes on carbon dioxide concentration levels in Kuwait classrooms. Energy Build. 2012, 47, 540-549. [CrossRef]

59. Teleszewski, T.; Gładyszewska-Fiedoruk, K. The concentration of carbon dioxide in conference rooms: A simplified model and experimental verification. Int. J. Environ. Sci. Technol. 2019, 16, 8031-8040. [CrossRef]

60. Persily, A.; Jonge, L. Carbon dioxide generation rates for building occupants. Indoor Air 2017, 27, 868-879. [CrossRef] [PubMed] 